\title{
Boreal fire records in Northern Hemisphere ice cores: a review
}

\author{
Michel Legrand ${ }^{1}$, Joseph McConnell ${ }^{2}$, Hubertus Fischer ${ }^{3}$, Eric W. Wolff ${ }^{4}$, Susanne Preunkert ${ }^{1}$, Monica Arienzo ${ }^{2}$, \\ Nathan Chellman ${ }^{2}$, Daiana Leuenberger ${ }^{3}$, Olivia Maselli ${ }^{2}$, Philip Place ${ }^{5}$, Michael Sigl $^{2}$, Simon Schüpbach $^{3}$, and \\ Mike Flannigan $^{6}$ \\ ${ }^{1}$ Université Grenoble Alpes, CNRS, Laboratoire de Glaciologie et Géophysique de l'Environnement (LGGE), \\ Grenoble, France \\ ${ }^{2}$ Division of Hydrologic Sciences, Desert Research Institute, Reno, Nevada, USA \\ ${ }^{3}$ Climate \& Environmental Physics, Physics Institute \& Oeschger Centre for Climate Change Research, \\ University of Bern, Bern, Switzerland \\ ${ }^{4}$ Department of Earth Sciences, University of Cambridge, Cambridge, UK \\ ${ }^{5}$ Department of Earth \& Environmental Sciences, University of Rochester, Rochester, New York, USA \\ ${ }^{6}$ Department of Renewable Resources, University of Alberta, Edmonton, AB, Canada \\ Correspondence to: Michel Legrand (michel.legrand@lgge.obs.ujf-grenoble.fr)
}

Received: 27 June 2016 - Published in Clim. Past Discuss.: 11 July 2016

Revised: 28 September 2016 - Accepted: 12 October 2016 - Published: 28 October 2016

\begin{abstract}
Here, we review different attempts made since the early 1990s to reconstruct past forest fire activity using chemical signals recorded in ice cores extracted from the Greenland ice sheet and a few mid-northern latitude, high-elevation glaciers. We first examined the quality of various inorganic (ammonium, nitrate, potassium) and organic (black carbon, various organic carbon compounds including levoglucosan and numerous carboxylic acids) species proposed as fire proxies in ice, particularly in Greenland. We discuss limitations in their use during recent vs. preindustrial times, atmospheric lifetimes, and the relative importance of other non-biomass-burning sources. Different high-resolution records from several Greenland drill sites and covering various timescales, including the last century and Holocene, are discussed. We explore the extent to which atmospheric transport can modulate the record of boreal fires from Canada as recorded in Greenland ice. Ammonium, organic fractions (black and organic carbon), and specific organic compounds such as formate and vanillic acid are found to be good proxies for tracing past boreal fires in Greenland ice. We show that use of other species - potassium, nitrate, and carboxylates (except formate) - is complicated by either post-depositional effects or existence of large non-biomassburning sources. The quality of levoglucosan with respect to other proxies is not addressed here because of a lack of highresolution profiles for this species, preventing a fair compar-
\end{abstract}

ison. Several Greenland ice records of ammonium consistently indicate changing fire activity in Canada in response to past climatic conditions that occurred during the last millennium and since the last large climatic transition. Based on this review, we make recommendations for further study to increase reliability of the reconstructed history of forest fires occurring in a given region.

\section{Introduction}

Biomass burning is a major source of gases and aerosols (Andreae and Merlet, 2001; Akagi et al., 2011) that strongly influence chemical composition of the atmosphere and the radiation balance. In turn, climate changes directly disturb the fire regime - for instance, through the frequency of lightning ignition following enhanced summer convective activity (Romps et al., 2014) - including the occurrence and duration of fire weather (Soja et al., 2007). Climate-induced changes in vegetation (e.g., changing vegetation type, species flammability, fuel mass) also may influence the fire regime (Hély et al., 2001). In this context, the boreal forest - a key carbon reservoir - is of particular interest because natural fires dominate in this region where future warming likely will significantly modify summer weather conditions. Whereas the mean burned forest area is expected to increase in the 
future in boreal regions (Flannigan et al., 2005), the change will not be spatially uniform and may differ from western to eastern North America and from North America to Siberia (Flannigan et al., 2001; Girardin et al., 2009). The availability of satellite data has strongly increased the accuracy of estimated burned areas (particularly for Siberian fires; Conard et al., 2002). Examination of present-day climate, fire conditions, and vegetation interactions, however, is complicated by the fact that, in addition to natural fires, many recent fires also are caused by human activities. Humans manage and extinguish fires, further complicating the spatial and temporal record of fire activity. Thus, we need to examine climate, fire conditions, and vegetation interactions through time prior to the appearance of human-origin fires at high northern latitudes to understand both natural and human impacts on past and present burning and improve predictions of future fire activity.

Charcoal deposited in lake and peat sediments is a generally accepted proxy for reconstructing fire occurrence in the past (Clark et al., 1996). Fire signals derived from charcoal analysis are dependent on the applied technique that either measures microscopic charcoal $(<100 \mu \mathrm{m})$ in pollen slides or macroscopic charcoal $(>200 \mu \mathrm{m}$ ) by sieving sediments (Carcaillet et al., 2002 and references therein). Whereas sieved macro-charcoal is representative of local-scale fire (typically a few hundred meters from the sampling site), microcharcoal from pollen slides is a proxy of regional burning history (up to $1 \mathrm{~km}^{2}$ around the sampling site; Carcaillet et al., 2001). Because of this limited spatial representativeness of charcoal records, several individual records must be assembled to derive a regional reconstruction of fire activity. In this way, paleo-fire records have been obtained at regional, continental, and global scales and can be compiled from the paleofire database for specific regions (Blarquez et al., 2014). Published North American paleo-fire compilations covering the Holocene, for example, already are available for four distinct regions (northwestern boreal, St. Lawrence, western US, and central North America) (Marlon et al., 2013).

Studies of the chemical composition of snow and ice allow examination of natural variability of the chemical composition of the past atmosphere; see Legrand and Mayewski (1997) for a review. Numerous chemical species emitted or produced in combustion plumes are trapped in glacial archives. Thus, ice cores can be used to reconstruct past fire activity, providing a tool complementary to charcoal records but with unrivalled dating precision in examining the link between climate and fire activity. We also emphasize that in high northern latitudes, charcoal records do not extend prior to $12 \mathrm{kyr} \mathrm{BP}$ since most of these regions were covered by ice. Potential fire proxies in ice are inorganic species (i.e., ammonium, nitrate, and potassium), as well as black carbon and numerous organic carbon species (or groups of species) that also are produced during combustion. These latter species include carbohydrates such as monosaccharide anhydrides (levoglucosan), aldehydes, short-chain (C1-C5) mono- and di-carboxylic acids, and acidic oligomers (humic-like substances). In addition, other organic molecules are specifically emitted during combustion of certain types of fuel: dehydroabietic acid produced by pyrolysis of conifer resin (Simoneit et al., 1993) and phenolic acids produced during incomplete combustion of conifers (vanillic acid) and grass ( $p$ hydroxybenzoic acid) (Simoneit et al., 2002).

Legrand et al. (1992) found that ice cores archive forest fire plumes by showing that the concentration of ammonium, formate, and oxalate (measured by ion chromatography, IC) in some summer layers deposited at Summit (central Greenland) greatly exceed their background levels. The authors attributed these ammonium/carboxylate events - mainly constituted by ammonium formate salt (ammonium to formate mass ratio of 0.4 ) - to transport of forest fire plumes from North America to the Greenland ice cap. Although the mechanism leading to formation of ammonium formate in biomass-burning plumes was not elucidated at that time, the presence of micro-soot particles identified by electron microscopy in one of these events confirmed the biomass-burning origin of these ammonium events (Legrand et al., 1995). Others confirmed the biomass-burning origin of ammonium formate events by atmospheric studies conducted at Summit showing a sudden increase in these chemical species in August 1994 and June 1993, when biomassburning plumes were transported to the site from northern Canada (Dibb et al., 1996; Jaffrezo et al., 1998). Finally, Kehrwald et al. (2012) showed that Summit snow layers corresponding to August 1994 Canadian forest fires exhibited, in addition to an oxalate peak, a large increase in levoglucosan, a carbohydrate specifically produced by cellulose burning.

Following these pioneering investigations, numerous studies have reported on past frequency of forest fires. Most of them were conducted in Greenland snow and ice, and often used different chemical proxies measured at different time resolution (sub-annual to multiple years). To date, using high-resolution (sub-annual) ammonium records obtained at central Greenland sites through the continuous flow analysis (CFA) technique, Fuhrer et al. (1996) investigated biomass burning for part of the Holocene (from 7.9 to $11.6 \mathrm{kyr} \mathrm{BP}$ and from $2.8 \mathrm{kyr} \mathrm{BP}$ to present) at Summit and Fischer et al. (2015) during the last glacial cycle (from 10 to $110 \mathrm{kyr}$ BP) at North GRIP. Because ammonium (but not formate) can be measured with CFA, high-resolution records of both ammonium and formate are few in number and limited to the last millennium since IC measurements and sub-annual sampling are required (Legrand and De Angelis, 1996; Savarino and Legrand, 1998).

Development of continuous black carbon (BC) measurement methods in ice cores (McConnell et al., 2007) based on new BC analyzers (SP2; Droplet Measurement Technologies, Boulder, Colorado) enabled precise, high-resolution measurements of $\mathrm{BC}$ in ice cores for the first time, adding an important new ice core indicator of biomass burning. The first high-resolution historical record of BC was developed 
from an ice core located at the western central Greenland site D4 and spanned the period 1788 to 2002. Complemented by high-resolution non-sea-salt sulfur determinations and the first high-resolution measurements of vanillic acid in ice cores, this initial $\mathrm{BC}$ record permitted evaluation of the contribution of biomass burning and fossil fuel combustion in Greenland snow deposited during the last two centuries, as well as related impacts on radiative forcing (McConnell et al., 2007). Alternatively, a low-resolution (5- to 50-year average) profile of levoglucosan covering the last $15 \mathrm{kyr}$ at the NEEM site in northwestern Greenland was used by Zennaro et al. (2015) to investigate boreal fire activity across millennial timescales. None of these studies, however, addressed three critical questions. First, how consistent are the fire records obtained at different Greenland sites (northern vs. central)? Second, did atmospheric transport between the source regions and drill site influence the record? Third, how reliable are different fire proxies given that they have different emission factors depending on combustion conditions and fuel nature, different atmospheric lifetimes, and some proxies which are not exclusively emitted by combustion? Finally, biomass-burning ice records were obtained at sites located in mid-latitude northern regions but they remain sparse and limited to the recent centuries; see Eichler et al. (2011) for a Siberian Altai glacier (the last 750 years), Kawamura et al. (2012) for a Kamchatka glacier (the last 300 years), and Müller-Tautges et al. (2016) in the Swiss Alps (the last 40 years).

In this paper, we first review available ice core chemical records of biomass burning focusing mainly on Greenland cores, exploring the quality of different proposed proxies, considering the intensity of their emission factor during combustion and their atmospheric behavior (lifetimes and budgets). We then compare several high-resolution (subannual) records extracted at different sites and scrutinize recent decades (1950-1990) during which meteorological data are available for backward air mass trajectory calculations and burned boreal forest area more accurately known. This comparison permits exploration of boreal source regions influencing the Greenland ice core records of forest fires and evaluation of the extent to which atmospheric transport influences these records. Although not recorded in all Greenland ice cores, the origin of the 1908 event (the year of the Tunguska phenomenon) is discussed. Some conflicting conclusions on long-term trends in boreal forest fires, in particular for the last millennium and last glacial-interglacial change, are discussed. Based on this review, we make recommendations for further studies to strengthen the quality of ice core records required to examine the relation between climate, vegetation, and fires in the past.

\section{Previously published and unpublished data}

Ice core studies from different Greenland sites that investigated past boreal forest fires are summarized in Table 1 . From north to south, the documented sites include NEEM $\left(77^{\circ} 26^{\prime} \mathrm{N}, 51^{\circ} 03^{\prime} \mathrm{W}\right)$, North GRIP $\left(75^{\circ} \mathrm{N}, 42^{\circ} \mathrm{W}\right)$, Summit $\left(72^{\circ} 36^{\prime} \mathrm{N}, 38^{\circ} 18^{\prime} \mathrm{W}\right)$, D4 $\left(71^{\circ} 24^{\prime} \mathrm{N}, 43^{\circ} 54^{\prime} \mathrm{W}\right)$, and $20 \mathrm{D}\left(65^{\circ} \mathrm{N}, 44^{\circ} 52^{\prime} \mathrm{W}\right)$. In addition to these published data, we used several unpublished seasonally resolved CFA records obtained by the Desert Research Institute (DRI) on firn and ice cores from some of the sites shown in Table 1 (NEEM-2011-S1, SUMMIT-2010, SUMMIT-2015Place, North GRIP2, and D4), and from the Humboldt site located in northwest Greenland $\left(78^{\circ} 31^{\prime} \mathrm{N}, 56^{\circ} 49^{\prime} \mathrm{W}\right.$; $1985 \mathrm{~m}$ a.s.1.; accumulation of $\left.14.4 \mathrm{~g} \mathrm{~cm}^{-2} \mathrm{yr}^{-1}\right)$. Other unpublished data used in this study were obtained in the field during the GRIP campaigns at Summit, including CFA measurements of ammonium and formaldehyde (Physics Institute and Oeschger Center for Climate Change Research at Bern), and IC investigations of short-chain mono- and dicarboxylates (Laboratory of Glaciologie et Géophysique de l'Environnement at Grenoble). Finally, recent and new chemical investigations, including ammonium (not shown), document biomass-burning fallout in ice cores extracted at the NEGIS (Vallelonga et al., 2014) and Tunu-2013 sites (Sigl et al., 2015). Ongoing studies conducted on northeast Greenland ice cores will complement results discussed here.

Details on sampling and methods generally can be found in publications referenced in Table 1. Following the very first investigations made by Hagler et al. (2007) in snowpit samples collected at Summit, new investigations have recently addressed the amount of organic carbon (OC) present in Greenland ice. Quantification of the dissolved organic carbon (DOC) content of ice on discrete samples was developed at LGGE using an ultraviolet (UV) oxidation and infrared (IR) quantification of $\mathrm{CO}_{2}$ with a commercial Phoenix 8000 system (Teledyne Tekmar Company, OH, USA). To remove contamination present on the outer portion of ice samples, a glass device was designed in which ice samples are washed with ultrapure water and melted afterward (Preunkert et al., 2011). During sample melting, an inert gas atmosphere is maintained inside the glass device to prevent contact of the ice sample with ambient air in the laboratory. These working conditions allow analysis of small $(5 \mathrm{~mL})$ samples containing less than $10 \mathrm{ppb} \mathrm{C}$ (Preunkert et al., 2011). They are, however, tedious (15 min required for cleaning and analysis of one sample) and difficult to apply for high-resolution Greenland ice records. Recent improvements in sample handling and other techniques in the CFA system at DRI enable arguably the first reliable high-resolution measurements of total organic carbon (TOC). In this new method, a Sievers 900 TOC analyzer is coupled to an ice core melter. The constantly flowing sample stream (isolated from any interaction with laboratory air and after minimal contact with plastics and other sources of contamination in the flow lines) is 


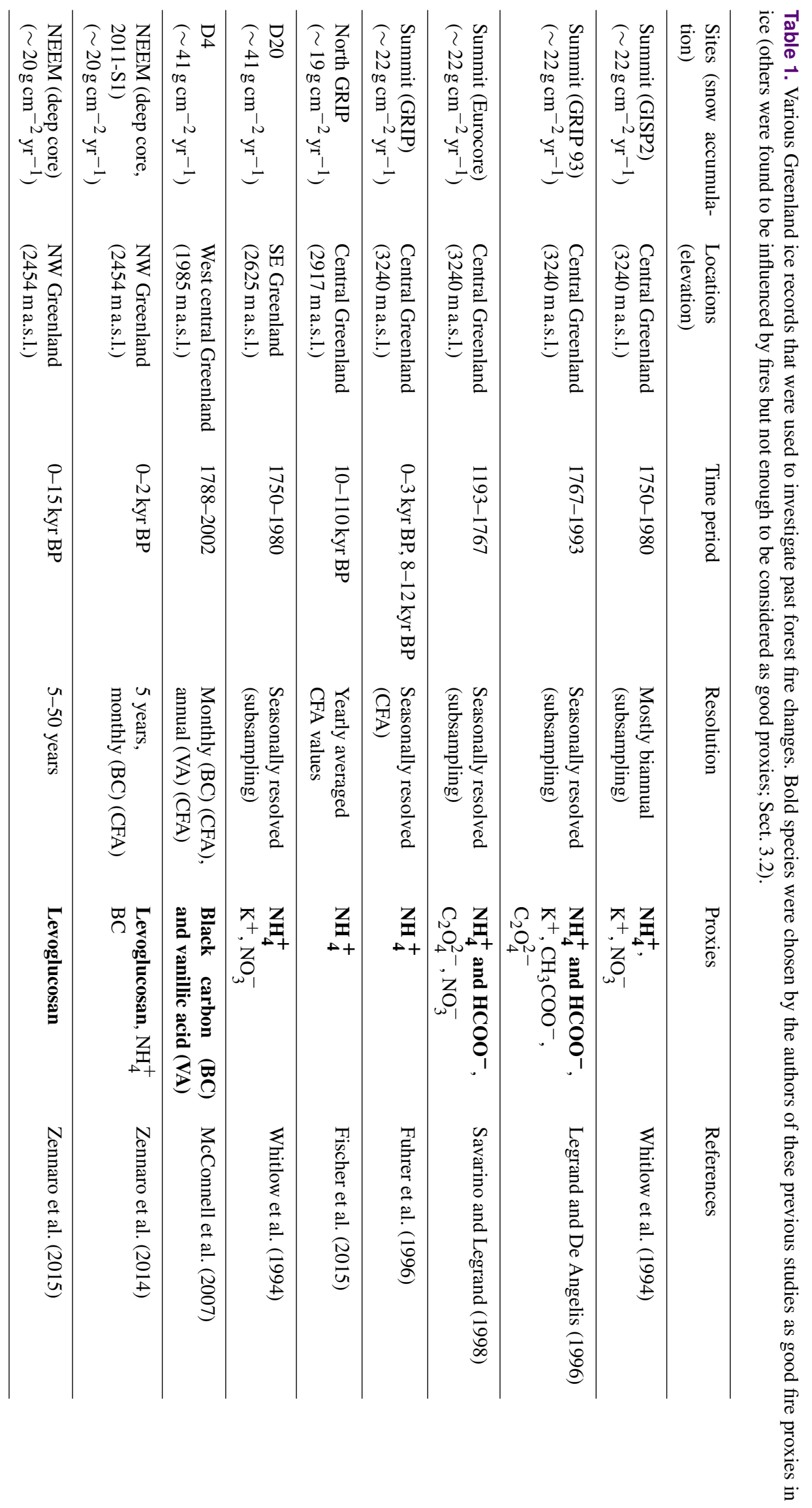


analyzed within a few minutes of initial melting. Total OC is determined in the Sievers 900 analyzer as the difference in total carbon and inorganic carbon. UV radiation and ammonium persulfate are used to oxidize organic compounds to $\mathrm{CO}_{2}$, and the $\mathrm{CO}_{2}$ is measured with a patented selective membrane-based conductometric detection method (details available in the Sievers 900 series total organic carbon analyzers, operation and maintenance manual, GE Analytical Instruments, 2011). We emphasize that for both DOC (Legrand et al., 2013) and TOC, measurements are most reliable in ice cores drilled without use of organic drilling fluids and in samples from below the pore close-off depth where potential contamination from circulating modern air through the core is eliminated.

\section{Chemical species emitted by combustion and fingerprint of forest fires in ice}

\subsection{Chemical composition of biomass-burning plumes}

For species identified in biomass-burning plumes, we summarize their origin in the plant biomass and their different chemical formation pathways (Fig. 1). Typically, the plant biomass contains $\mathrm{C}(45 \%), \mathrm{O}(45 \%), \mathrm{H}(6 \%), \mathrm{N}(1.5 \%)$, $\mathrm{K}(1 \%), \mathrm{Ca}(0.5 \%), \mathrm{S}(0.1 \%)$, and $\mathrm{Cl}(0.01 \%)$ (Raven et al., 2007). At any time, a vegetation fire may proceed under both flaming and smoldering conditions. During flaming (around $1100^{\circ} \mathrm{C}$ ) that dominates in the earlier phase of the fire, $\mathrm{C}, \mathrm{H}$, and $\mathrm{N}$ present in fuel are converted into highly oxidized simple molecules $\left(\mathrm{H}_{2} \mathrm{O}, \mathrm{CO}_{2}, \mathrm{~N}_{2}\right.$, and $\left.\mathrm{NO}\right)$. Most $\mathrm{BC}$ also is produced at this stage. Later, smoldering conditions (below 230 to $430^{\circ} \mathrm{C}$ ) tend to become dominant, leading to emission of most of the $\mathrm{CO}$, non-methane hydrocarbons (NMHCs), and primary OC aerosol. Concerning the OC fraction, identification of individual species in many studies often is limited to short-chain mono- and di-carboxylates that represent less than $10 \%$ of total OC mass (e.g., Ruellan et al., 1999). Following Simoneit et al. (1999) who identified levoglucosan as a tracer of cellulose in biomass burning, several studies conducted in combustion plumes extended OC speciation to this carbohydrate. To our knowledge, the most extended OC speciation was obtained for savannah fires (Gao et al., 2003) where, in addition to carbohydrates like levoglucosan and glucose, gluconic acid was tentatively identified as the most important carboxylate. At temperatures higher than $400^{\circ} \mathrm{C}$, levoglucosan can be thermally destroyed into either smaller compounds producing various aldehydes and carboxylic acids or repolymerized into polysaccharides to then form high molecular organic-containing bonds and carbonyl groups (i.e., similar to humic-like substances; Fig. 1) (Kawamoto et al., 2003; Abella et al., 2007). Finally, in addition to these primary emissions, numerous NMHCs and oxygenated volatile organic compounds (OVOCs) emitted during combustion will be oxidized into small carboxylic acids (Fig. 1). In contrast to combustion of fossil fuels, the rela- tively low temperature of biomass burning compared to fossil fuel combustion leads to emission of nitrogen (mostly NO and $\mathrm{NH}_{3}$ ) mainly originating as nitrogen present in fuel (not as atmospheric $\mathrm{N}_{2}$ ). Potassium, a major electrolyte in plant cytoplasm, is easily volatilized during combustion (boiling point of $760{ }^{\circ} \mathrm{C}$ against $1484^{\circ} \mathrm{C}$ for calcium, for instance).

As discussed, emission of many species often depends on combustion conditions, particularly for organic compounds. The content of burned matter is another important parameter for many inorganic compounds. Quantification of emission factors, defined as the mass of species emitted per kilogram of dry matter (DM) burned, during combustion of different types of vegetation highlights some specific characteristics of boreal fires. For most species reported in Fig. 1, emission factors for savannah as well as tropical and extratropical forests (including boreal and temperate fires) can be found in Andreae and Merlet (2001). More recently, data have become available for some species distinguishing between temperate and boreal fires (Akagi et al., 2011). The case of nitrogen emissions is a good example of the need to get data distinguishing temperate from boreal fires. Indeed, whereas Andreae and Merlet (2001) reported an emission factor 2fold higher for $\mathrm{NO}$ than for $\mathrm{NH}_{3}$ ( $3 \mathrm{~g}$ of $\mathrm{NO}$ against $1.4 \mathrm{~g}$ of $\mathrm{NH}_{3}$ per kilogram of DM) for extratropical fires, Akagi et al. (2001) reported emission factors of $2.7 \mathrm{~g}$ for $\mathrm{NH}_{3}$ against $0.9 \mathrm{~g}$ for NO per kilogram of DM for boreal fires $(0.8 \mathrm{~g}$ of $\mathrm{NH}_{3}$ against $2.5 \mathrm{~g}$ for $\mathrm{NO}$ per kilogram of $\mathrm{DM}$ for temperate fires). Thus, one of the most important emission features from boreal fires lies in nitrogen emissions dominated by ammonia but not $\mathrm{NO}_{x}$ emissions. For potassium, although no data are available for boreal fires, Andreae and Merlet (2001) reported emission factors ranging between 0.1 and $0.4 \mathrm{~g}$ of potassium per kilogram of DM for extratropical fires. Potassium emission factors are not expected to be strongly dependent on fire combustion (McMeeking et al., 2009) but more on potassium content of the fuel. For organic compounds (NMHCs, OVOCs, and OC primary aerosol), smoldering conditions that are predominant in boreal fires can generally lead to higher emission factors than other vegetation fires. Only available for boreal fires are emission factors for NMHCs and OVOCs (a total of $59 \mathrm{~g}$ vs. $24 \mathrm{~g} \mathrm{~kg}^{-1}$ of DM for temperate fires; Akagi et al., 2011). These emissions of NMHCs and OVOCs play a key role as precursors of shortchain carboxylates, representing a large source of secondary OC aerosol (Fig. 1). For carbonaceous aerosol (BC and OC), laboratory experiments by McMeeking et al. (2009) show that, as expected, twice more $\mathrm{BC}$ is emitted under flaming conditions than under mixed conditions (flaming and smoldering) (1.0 g of BC per kilogram of DM for flaming and $0.5 \mathrm{~g}$ of $\mathrm{BC}$ per kilogram of DM for mixed conditions). Alternatively, far less $\mathrm{OC}$ is emitted under flaming conditions (1.6 g of OC per kilogram of DM for flaming and $16 \mathrm{~g}$ of OC per kilogram of DM for mixed conditions). Finally for levoglucosan, although less data are available, Andreae and Merlet (2001) reported emission factors of $0.75 \mathrm{~g}$ of levoglu- 


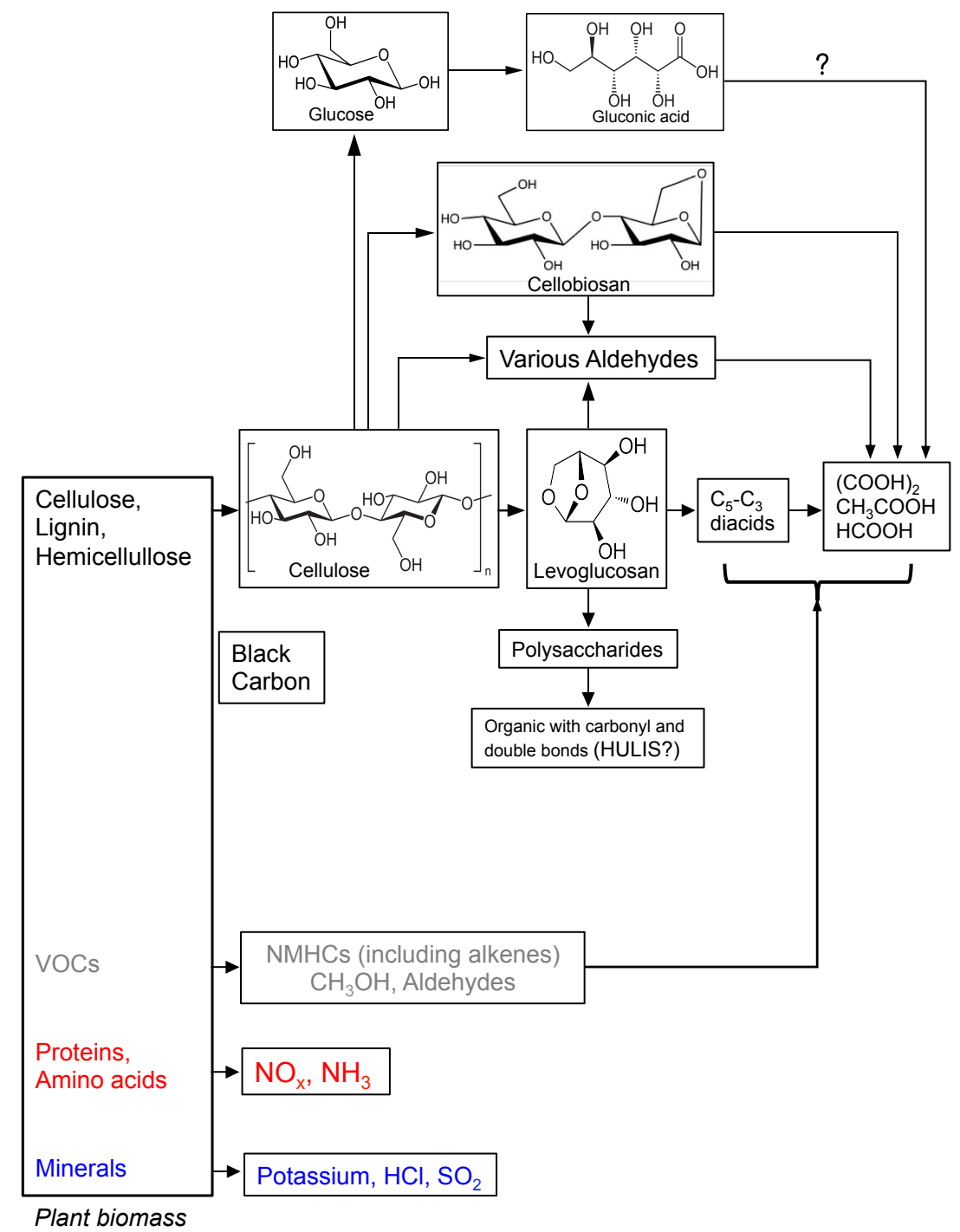

Figure 1. Proposed chemical pathways for formation of various chemical species identified in smoke aerosols. Adapted from Gao et al. (2003) and references therein, Kawamoto et al. (2003), and Abella et al. (2007).

cosan per kilogram of DM for extratropical fires vs. 0.28 for savannah. The expected dependency of emission factors of levoglucosan with combustion conditions characterized by a quasi-zero emission during flaming, as observed by Gao et al. (2003) for savannah fires, was confirmed by laboratory experiments (Dhammapala et al., 2007; Kuo et al., 2008).

\subsection{Fingerprint of forest fires in Greenland ice}

With the goal to reconstruct past forest fire activity, ammonium has been used extensively to document fires in numerous Greenland ice cores at sub-annual resolution (Table 1). Many of these studies also documented nitrate and occasionally soluble potassium deposition. These high-resolution studies sometimes documented BC and some organic acids (particularly $\mathrm{C} 1-\mathrm{C} 2$ carboxylic and vanillic acid). Other
Greenland records exist for levoglucosan but only at low resolution (Table 1). Since fires are episodic in nature, we first focus our discussion on ammonium, short-chain carboxylates, BC, nitrate, and potassium for which several highresolution Greenland profiles are available. The case of levoglucosan is discussed in Sect. 4.2 and 4.3.

High-resolution chemical profiles were obtained in Greenland ice cores by employing either IC analysis on discrete samples or CFA techniques (Table 1). The first records were achieved by subsampling pieces of firn and ice (several samples per year) with subsequent analysis by IC permitting investigations of potentially relevant species (e.g., ammonium, potassium, nitrate, and several light carboxylates including formate, acetate, glycolate, and oxalate). A second set of profiles was achieved using CFA - permitting investigation 
of high-resolution records of ammonium, nitrate, formaldehyde, BC, and sometimes vanillic acid.

Legrand and De Angelis (1996) found that the firn material is very sensitive to contamination for carboxylates during standard storage of cores in sealed plastic bags. To minimize this problem, a firn core (73 m depth) drilled at Summit in 1993 (Legrand and De Angelis, 1996) was processed in the field by shaving around $90 \%$ of the outer part of firn core sections within one or two hours after extraction. Note that this record still represents the only profile documenting carboxylates during recent decades in Greenland snow. In order to examine the chemical signature of ammonium events with respect to background levels, data from this firn core were used to examine the relationship between ammonium and nitrate as well as between ammonium and the different carboxylates (Fig. 2). Anthropogenic emissions impacting the budget of nitrate and carboxylates in Summit snow layers led us to restrict our examination to the pre-1940 time period (520 samples). Indeed, the level of nitrate between 1250 and 1940 AD (60 \pm 17 ppb; Savarino and Legrand, 1998) was enhanced to $99 \pm 37 \mathrm{ppb}$ during recent decades as a result of growing $\mathrm{NO}_{x}$ emissions (Mayewski et al., 1990; Fischer et al., 1998). Furthermore, Legrand and De Angelis (1996) demonstrated that the levels of formate close to $9 \pm 3$ ppb between 1750 and 1940 have decreased to $6 \pm 2 \mathrm{ppb}$ as a result of acidification of the atmosphere following emission of $\mathrm{SO}_{2}$ and $\mathrm{NO}_{x}$. In Fig. 2, we used data obtained along pieces of ice (660 samples) from the deep GRIP ice core and corresponding to the Holocene period (Legrand and De Angelis, 1995, 1996).

In the following sections, we compare the different potential biomass-burning proxies to ammonium. In addition to the fact that many more high-resolution records are available for ammonium than for any other chemical species, the choice of ammonium as the reference species is legitimate since its non-biomass-burning background summer level in Greenland ice is relatively low (less than $18 \mathrm{ppb}$; Legrand et al., 1992). Estimates of the non-biomass-burning ammonium level were derived from simultaneous comparisons of formate and ammonium levels, exploiting the fact that forest fire debris reaching Greenland mainly consists of ammonium formate and that formate background levels in Greenland ice exhibit low temporal variability. These features are confirmed in Fig. $2 \mathrm{a}$ and $\mathrm{b}$.

\subsubsection{Ammonium and carboxylates}

As shown in Fig. 3, ammonium peaks are accompanied by a simultaneous increase in formate, oxalate, and sometimes nitrate and potassium. For glycolate and acetate, the snow or ice layers located in the vicinity of the ammonium peak also are disturbed. The presence of these wider peaks for glycolate and acetate than for ammonium likely are related to post-depositional processes acting on these two volatile species. A similar smoothing of formaldehyde (HCHO) fall- out related to biomass-burning events also was reported by Fuhrer et al. (1993), as seen in Fig. 4. Therefore, in examining the relationship between ammonium and carboxylates in Fig. 2, we used glycolate and acetate concentrations in samples corresponding to the background and peak but discarded those in the neighboring layers of the ammonium peaks (i.e., 27 values of 524 during the 1773 to 1940 time period and 30 values of 630 during the Holocene). Figure 2 shows that formate unambiguously increases well above its background level during ammonium events. The ammonium events also are accompanied by enhancement above background values for glycolate, and to a lesser extent oxalate, whereas for acetate the enhancement remains within the range of background variability (Fig. 2).

To compare deposition of carbon associated along ammonium events, we calculate enhancement of the different carboxylates above their respective background values for different ammonium events (Fig. 5). For species exhibiting broadening with respect to the ammonium peak (acetate and glycolate), we considered total deposition by calculating the total area of the perturbation. The same procedure was applied to formaldehyde data available along a few ammonium events, such those reported in Fig. 4. Using the slope of the linear regression between ammonium and carboxylates (expressed in carbon mass) plotted in Fig. 5 (formate: $\left[\mathrm{HCOO}^{-}\right]=0.65\left[\mathrm{NH}_{4}^{+}\right] R^{2}=0.86$, acetate: $\left[\mathrm{CH}_{3} \mathrm{COO}^{-}\right]=0.07\left[\mathrm{NH}_{4}^{+}\right] R^{2}=0.32$, glycolate: $\left[\mathrm{CH}_{2} \mathrm{OHCOO}^{-}\right]=0.105\left[\mathrm{NH}_{4}^{+}\right] R^{2}=0.69$, and oxalate: $\left.\left[\mathrm{C}_{2} \mathrm{O}_{4}^{2-}\right]=0.025\left[\mathrm{NH}_{4}^{+}\right] R^{2}=0.45\right)$, and the one calculated for formaldehyde $\left([\mathrm{HCHO}]=0.02\left[\mathrm{NH}_{4}^{+}\right] R^{2}=0.86\right.$, not shown), we estimate that input of formate accounts alone for $74 \%$ of the total mass of identified OC species followed by glycolic acid (12\%), and acetic acid (8\%), HCHO and oxalate each accounting for $3 \%$. This dominant presence of formate in ammonium-rich Greenland deposits contrasts with the relatively weak emission factors reported for boreal fires $(0.16 \mathrm{~g} \mathrm{C}$ for formic acid against $1.8 \mathrm{~g} \mathrm{C}$ for acetic acid per kilogram of DM; Akagi et al., 2011). This reflects the importance of secondary production of formic acid during aging of the plume (Lefer et al., 1994).

Figure 5 includes a few data corresponding to ammonium events that occurred during the Younger Dryas (11600$12600 \mathrm{yr} \mathrm{BP})$; these are shown as triangles. Of the four events reported in the formate panel, we estimate enhancement above background levels for only one event because of lack of available ice samples adjacent to the event. This fully documented Younger Dryas event, with an ammonium peak reaching $145 \mathrm{ppb}$, indicates no enhancement of glycolate (Fig. 5). In fact, in the deep GRIP ice core, the background level of this carboxylate gradually decreases through time, from $1.3 \pm 2.6 \mathrm{ppb}$ during the last $5 \mathrm{kyr}$ to $0.3 \pm 0.9 \mathrm{ppb}$ between 5 and $10 \mathrm{kyrBP}$ and zero prior to $11 \mathrm{kyrBP}$ (not shown). This decreasing trend is not related to past climate changes since, even during the preceding warm period (the 

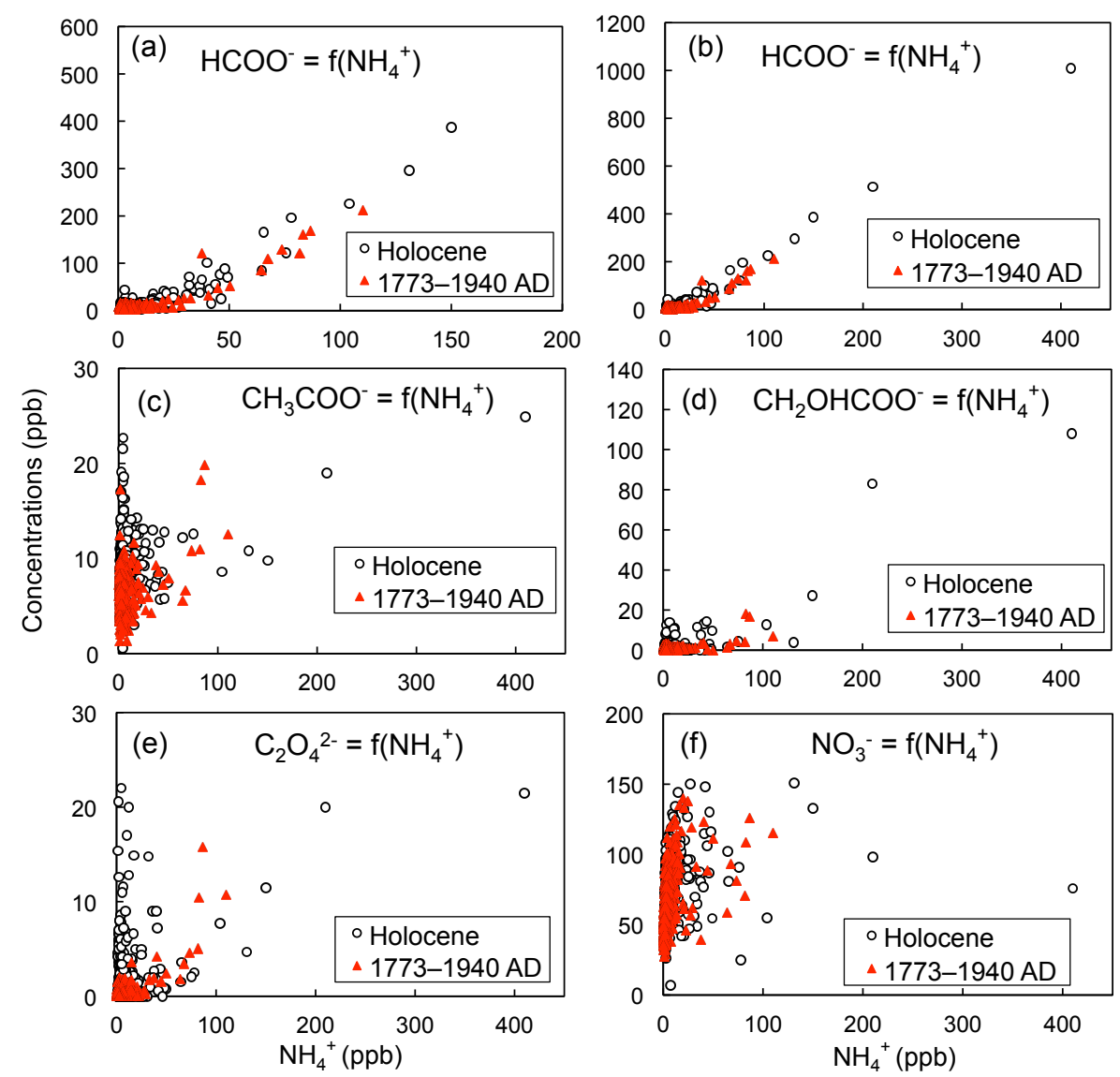

Figure 2. Concentrations of various carboxylates $(\mathbf{a}-\mathbf{e})$ and nitrate $\left(\mathrm{NO}_{3}^{-}\right)$, (f) as a function of ammonium $\left(\mathrm{NH}_{4}^{+}\right)$in Summit snow and ice layers. $\mathrm{HCOO}^{-}$is formate, $\mathrm{CH}_{3} \mathrm{COO}^{-}$is acetate, $\mathrm{CH}_{2} \mathrm{OHCOO}^{-}$is glycolate, and $\mathrm{C}_{2} \mathrm{O}_{4}^{2-}$ is oxalate. For formate, two panels $(\mathbf{a}$ and $\mathbf{b})$ are shown to detail the relationship at ammonium concentrations lower than $200 \mathrm{ppb}$ (a). The red triangles correspond to the layers deposited between 1773 and 1940 AD (520 values along the GRIP 93 firn core: Table 1); the black circles correspond to the Holocene period along the GRIP deep ice core (660 values between and 355 and $11600 \mathrm{yr} \mathrm{BP}$ ).

Eemian at around $120000 \mathrm{yr} \mathrm{BP}$ ), glycolate was still not detected in ice, whereas all other carboxylates are in the range of values seen during the Holocene. We therefore conclude that this species slowly degraded in the ice.

Although present at concentrations well below those of organic compounds (less than $1 \mathrm{ppb}$ ) discussed above, vanillic acid was investigated using CFA in Greenland snow layers (e.g., at D4; McConnell et al., 2007) with the aim of attributing the contributions of fossil fuel and biomass burning to the budget of $\mathrm{BC}$ during the last two centuries. We report annual levels of vanillic acid and ammonium in snow layers deposited at D4 between 1740 and 1870 (Fig. 6). Although formate was not measured in D4 snow, comparisons of temporal variability indicate that vanillic acid also can be used as a surrogate of ammonium $\left(R^{2}=0.62\right.$ for vanillic acid vs. ammonium, compared to $R^{2}=0.87$ for formate vs. ammonium at Summit).

\subsubsection{Ammonium vs. formate and nitrate}

Whitlow et al. (1994) and Savarino and Legrand (1998) found that some (but not all) $\mathrm{NH}_{4}^{+}$events in the Summit layers are accompanied by a moderate increase (a few tens of parts per billion) in nitrate. Figure 3 illustrates this with the 1863 ammonium event showing an increase of nitrate $(\sim 40$ $50 \mathrm{ppb}$ ) but not the 1908 event. Figure 2 suggests that, if it exists, an input of nitrate accompanying ammonium events remains in the range of variability of nitrate background levels. The variability of nitrate background level in Summit snow layers is mainly related to the seasonal change with values close to $50 \mathrm{ppb}$ in winter and $90 \mathrm{ppb}$ in summer. Although the budget of nitrate in pre-industrial Greenland ice has not been discussed yet, it is likely that the summer maximum is related to natural NO sources like soil emissions from surrounding continents and possibly lightning, both being more active in summer than winter. Figure 2 does not support use of nitrate in Greenland ice as a proxy of forest fires. 

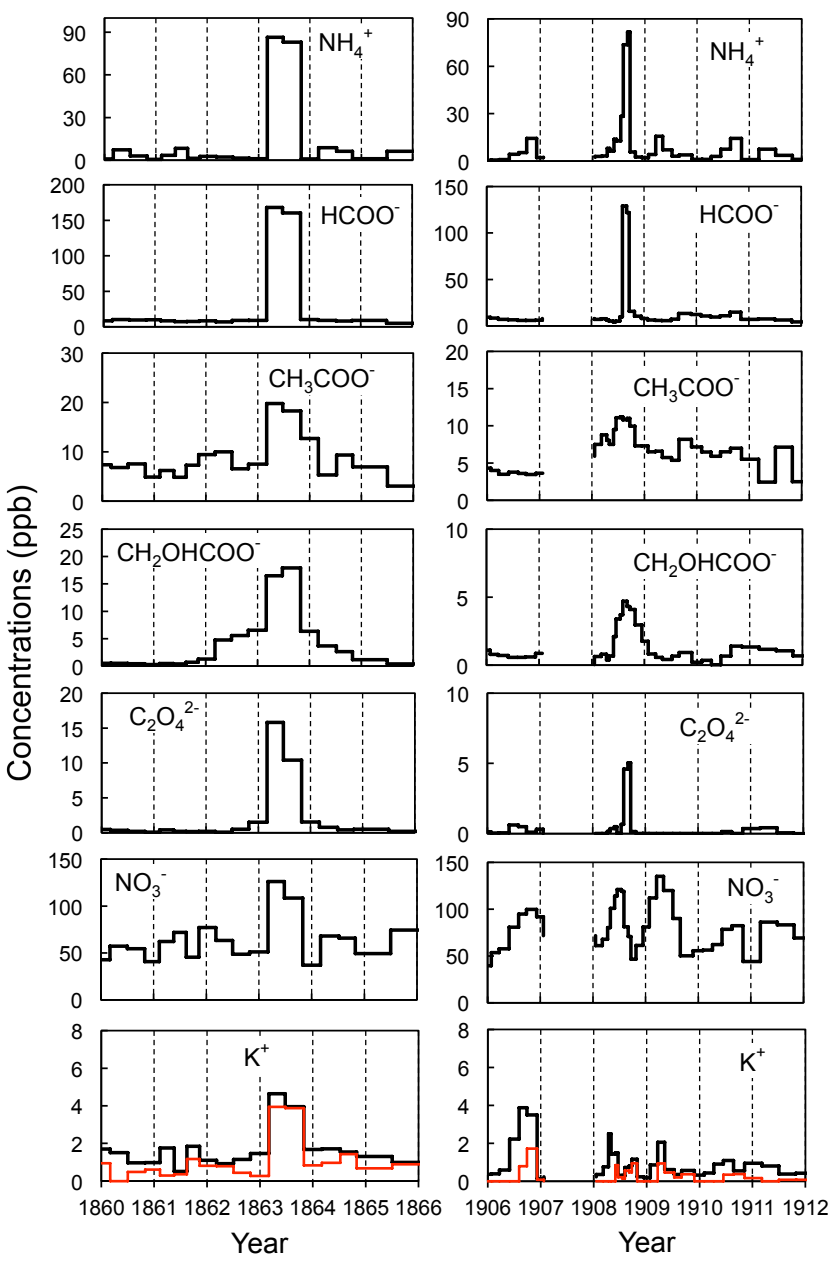

Figure 3. Chemical fingerprint of two ammonium events dated in the GRIP 93 firn core at 1863 AD (left) and 1908 AD (right). $\mathrm{NH}_{4}^{+}$is ammonium, $\mathrm{HCOO}^{-}$is formate, $\mathrm{CH}_{3} \mathrm{COO}^{-}$is acetate, $\mathrm{CH}_{2} \mathrm{OHCOO}^{-}$is glycolate, $\mathrm{C}_{2} \mathrm{O}_{4}^{2-}$ is oxalate, $\mathrm{NO}_{3}^{-}$is nitrate, and $\mathrm{K}^{+}$is soluble potassium. For soluble potassium, the black and red curves refer to total and fine fraction, respectively (Sect. 3.2.3).

While Legrand and De Angelis (1996) reported a formateto-ammonium molar ratio close to unity in $\mathrm{NH}_{4}^{+}$events recorded at Summit both during the last 200 years and the Holocene, Savarino and Legrand (1998) showed that from 1190 to 1770 , more ammonium events were accompanied by a significant increase in nitrate. The input of nitrate plus formate equilibrates the ammonium input on a molar basis. The departure from unity of the ammonium to formate molar ratio in snow remains more an exception than an overall rule (Fig. 7). With an emission factor of $2.7 \mathrm{~g}$ of $\mathrm{NH}_{3}$ against $0.9 \mathrm{~g}$ for NO per kilogram of DM in boreal fire emissions (see Sect. 3.1.), we would expect ammonium to dominate nitrate by a factor of 5 on a molar basis. The even larger observed dominance of ammonium in forest fire debris deposited in Greenland snow suggests that, in addition to emission factors of the two species, another parameter tends to minimize de- position of nitrate. Aircraft-based sampling completed during the NASA Arctic Boundary Layer Expedition (ABLE 3B) indicated an $\mathrm{HNO}_{3}$ mixing ratio of $200-400$ pptv against 1300-3000 pptv of formic acid and 1700-3000 pptv of acetic acid (Lefer et al., 1994). A detailed study of $\mathrm{NO}_{y}$ partitioning in boreal biomass-burning plumes was completed by Alvarado et al. (2010) in the framework of Artic Research of the Composition of the Troposphere from Aircraft and Satellite (ARCTAS-B), showing that PAN is the dominant $\mathrm{NO}_{y}$ species well above $\mathrm{HNO}_{3}$. We also emphasize that the relative abundance of $\mathrm{NO}$ with respect to $\mathrm{NH}_{3}$ would depend on the altitude of the plume. We expect that most NO emissions take place during flaming when release of energy is at its maximum, sometimes permitting plumes to reach the upper troposphere by pyro-convection. These events are rare, and boreal fire plumes are generally observed between 2 and $7 \mathrm{~km}$ (de Gouw et al., 2006).

Using the tropospheric emission spectrometer aboard the NASA Aura satellite, Alvarado et al. (2011) reported $\mathrm{NH}_{3}$ mixing ratios of several parts per billion by volume (up to 7 ppbv) in fresh biomass-burning plumes in July 2008 over central Canada. Similarly, $\mathrm{HCOOH}$ mixing ratios ranging from 1 to $2.4 \mathrm{ppbv}$ were observed. Given the dominant presence of these two gases in these boreal fire plumes, we may expect that - during transport toward Greenland - a neutralization of ammonia by formic acid would take place through in-cloud processes. Since satellite data indicate that ammonia is present in excess with respect to acidic species, it is likely that the neutralization process can continue until the secondary production of $\mathrm{HCOOH}$ from the oxidation of $\mathrm{NMHCs}$ and OVOCs stops. This may explain the quasi-invariant presence of ammonium formate in Greenland snow and ice layers impacted by boreal forest fire plumes.

\subsubsection{Ammonium vs. potassium}

In the atmosphere, the fine fraction of soluble potassium is thought to be related to biomass combustion (Cachier et al., 1991). In the ice, this fraction can be estimated by subtracting both the contribution of sea salt by using sodium level $\left([\mathrm{K}]_{\text {sea salt }}=0.038[\mathrm{Na}]\right)$ and of dust by using calcium from the potassium present in ice (and measured with IC). For the latter contribution, Legrand and De Angelis (1996) derived a $\mathrm{K}^{+} / \mathrm{Ca}^{2+}$ mass ratio of 0.04 based on the observed linear correlation in snow layers free of biomassburning inputs along the GRIP 1993 firn core. In Fig. 3, the fine fraction calculated on this basis (i.e., $\left[\mathrm{K}^{+}\right]_{\mathrm{bb}}=\left[\mathrm{K}^{+}\right]-$ $\left.0.038 \times\left[\mathrm{Na}^{+}\right]-0.04 \times\left[\mathrm{Ca}^{2+}\right]\right)$ is reported for the ammonium events dated at Summit in 1908 and 1863. While for the 1863 event, an increase of potassium in the range of $2 \mathrm{ppb}$ is detected, no significant change is detected for the 1908 event. Examination of the relationship between fine potassium and ammonium for ammonium events occurring between 1770 and 1890 confirms such a relatively poor relationship $\left(\left[\mathrm{K}^{+}\right]_{\mathrm{bb}}=0.15+0.03 \times\left[\mathrm{NH}_{4}^{+}\right]\right.$with $\left.R^{2}=0.3\right)$. 


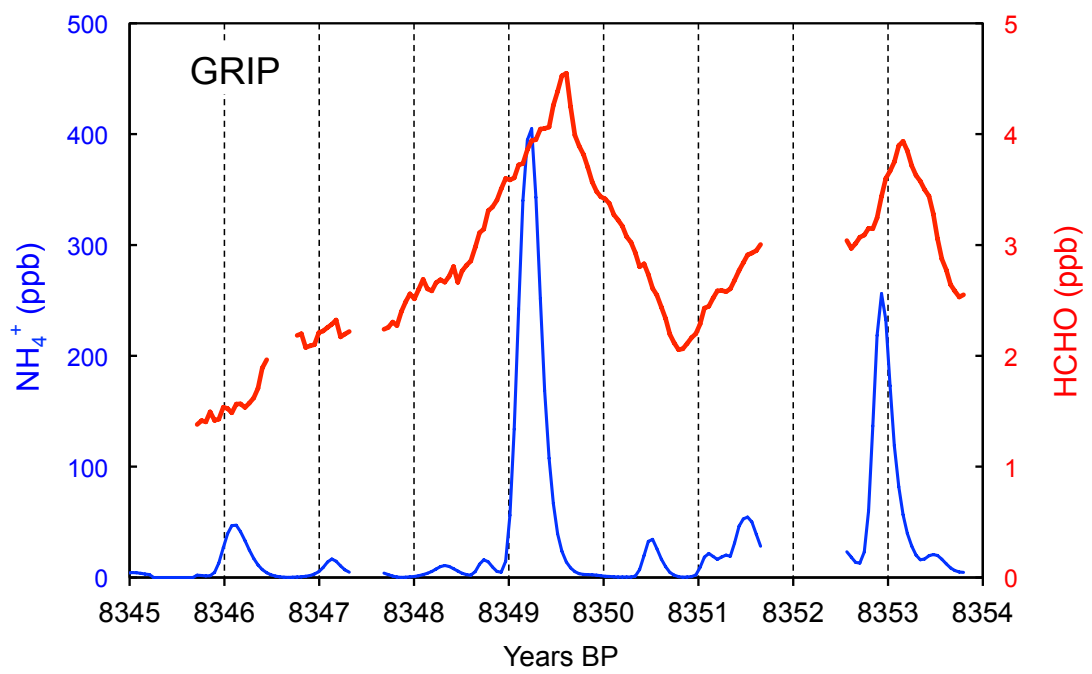

Figure 4. An example of formaldehyde (HCHO) perturbations detected at Summit (GRIP deep ice core) along two ammonium events.
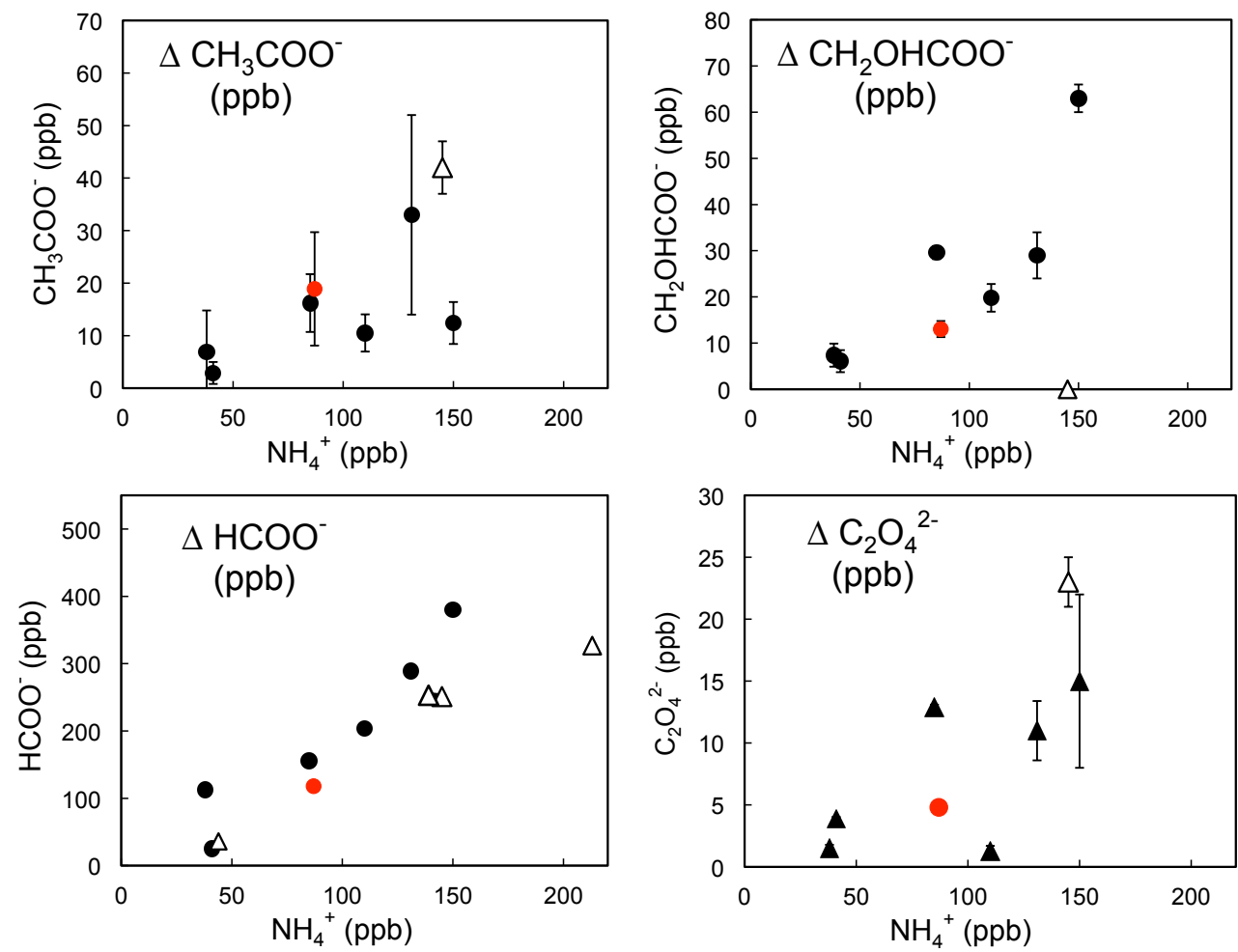

Figure 5. Enhancement of carboxylates above their background levels as a function of ammonium along several fire events detected in snow and ice layers deposited at Summit (GRIP 93 firn core and the deep GRIP ice core). $\mathrm{HCOO}^{-}$is formate, $\mathrm{CH}_{3} \mathrm{COO}^{-}$is acetate, $\mathrm{CH}_{2} \mathrm{OHCOO}^{-}$is glycolate, and $\mathrm{C}_{2} \mathrm{O}_{4}^{2-}$ is oxalate. The black circles refer to events that occurred during the Holocene (0-11 400 yr BP); the red dots refer to the $1908 \mathrm{AD}$ event shown in Fig. 3. Open triangles correspond to four ammonium events that occurred during the Younger Dryas (11 600 to $12600 \mathrm{yr}$ BP). For acetate and glycolate, calculation of enhancements considered the smoothing of the perturbation around the ammonium perturbation. Vertical bars are uncertainties in calculating the enhancements above background values.

Furthermore, even along the largest ammonium event of the Holocene $\left(\mathrm{NH}_{4}^{+}\right.$concentrations reaching $410 \mathrm{ppb}$; Fig. 2), enhancement of potassium remained limited to $2 \mathrm{ppb}$ (not shown) instead of $12 \mathrm{ppb}$ if the preceding linear relationship is considered. Data from Summit therefore suggest that soluble potassium concentrations in snow and ice are enhanced 

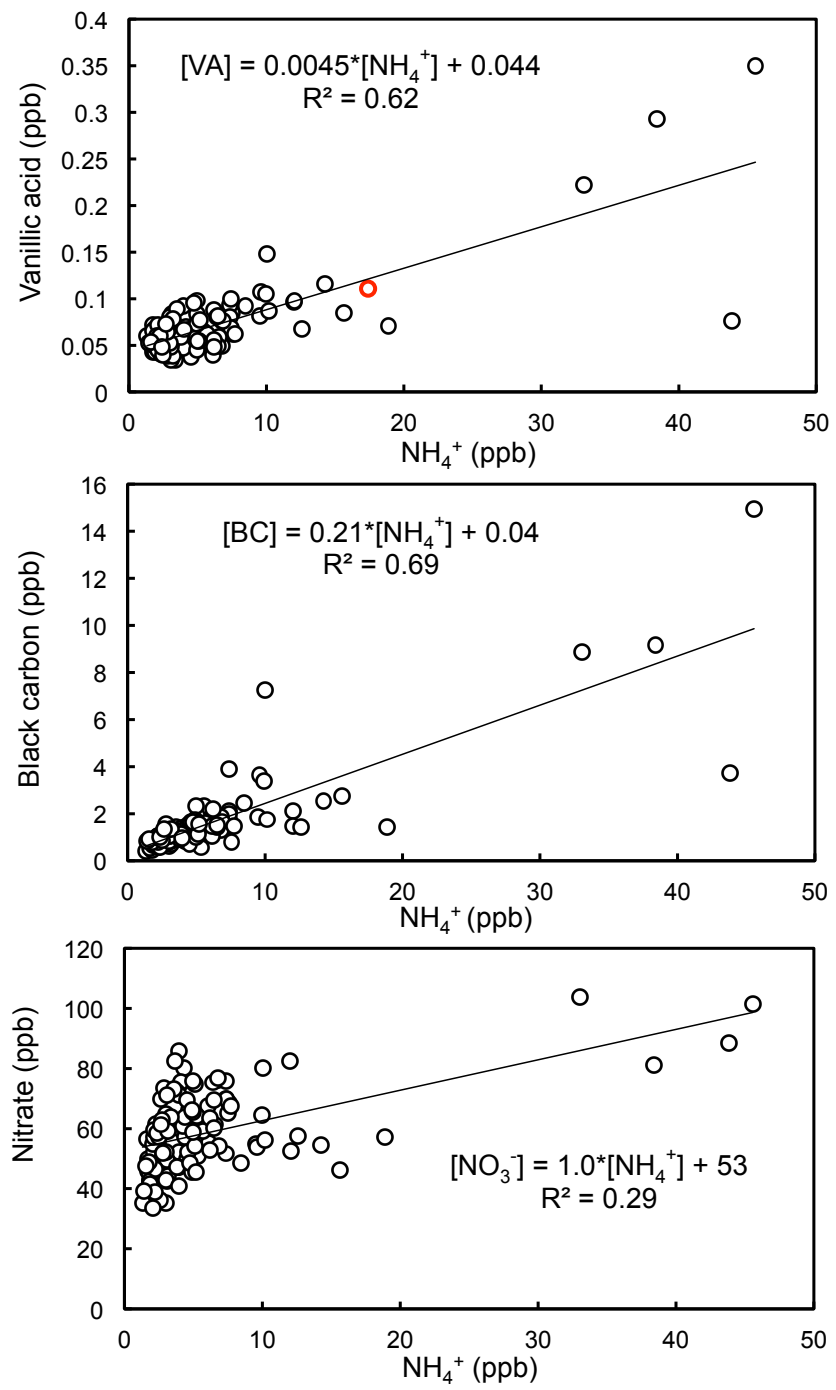

Figure 6. Annual mean concentrations of vanillic acid, BC, and nitrate vs. ammonium in snow layers deposited at D4 during preindustrial times (from 1740 to 1870). For vanillic acid, we also report the point corresponding to the 1908 event (red circle).

by a few parts per billion along some (but not all) ammonium events. Given the high sensitivity of this species to contamination (Savarino and Legrand, 1998), it remains difficult to promote use of potassium as a proxy of boreal fires.

\subsubsection{Ammonium vs. $\mathrm{BC}$ and $\mathrm{OC}$}

The correlation between ammonium and $\mathrm{BC}$ remains relatively strong $\left(R^{2}=0.69\right.$, Fig. 6$)$, although slightly weaker than the one between ammonium and formate $\left(R^{2}=0.87\right.$ at Summit). At least for the Greenland sites discussed here, the ammonium formate peaks always stay in summer snow layers without spreading to the rest of the year, in contrast to what is observed for formaldehyde and acetate (Sect. 3.2.1). We can, therefore, rule out that remobilization of ammonium

formate after deposition (not foreseen for the irreversibly trapped $\mathrm{BC}$ species) renders the relationship between ammonium and $\mathrm{BC}$ weaker than the one between ammonium and formate. The most likely cause of the slightly weaker BC$\mathrm{NH}_{4}^{+}$relationship compared to that of formate and ammonium is that flaming (the most important combustion phase for $\mathrm{BC}$ ) is not the dominant phase in boreal fires, rendering the amount of $\mathrm{BC}$ reaching the Greenland ice cap variable from one event to another.

Apart from a snowpit study of recent snow layers deposited at Summit (Hagler et al., 2007), data on the OC content of Greenland ice are rare. A few investigations of the amount of OC present in Greenland ice were first accomplished using an UV oxidation and IR quantification of $\mathrm{CO}_{2}$ (Preunkert et al., 2011). Deployed for the examination of 

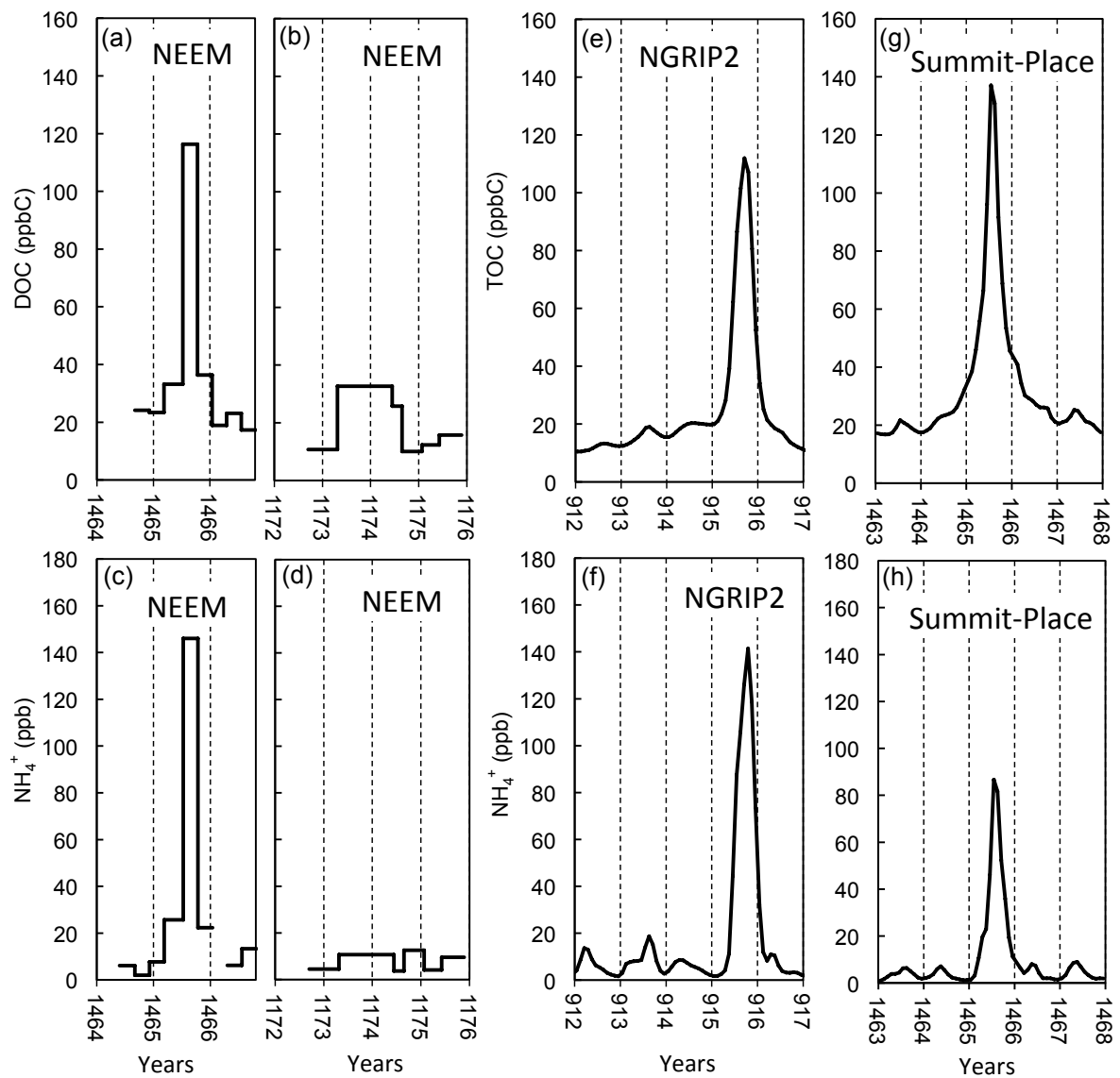

Figure 8. Example of OC changes along fire events in Greenland ice. Panels (a) to (d) are from the NEEM-2011-S1 ice core for which OC was measured with a UV oxidation method (Sect. 2) and ammonium on discrete samples analyzed with ion chromatography. Panels (e) to (h) are from North GRIP2 and Summit-Place (collected in 2015) ice for which ammonium was measured with a CFA system and OC was investigated with a CFA coupled to a total organic carbon analyzer (Sect. 2). The NEEM-2011-S1 and North GRIP2 cores were drilled with organic drilling fluid and the Summit-2015-Place core without.

an ammonium event in the NEEM-2011-S1 core, Legrand et al. (2013) showed that the OC background level close to $15-20 \mathrm{ppb} \mathrm{C}$ was enhanced by $\sim 100 \mathrm{ppb} \mathrm{C}$ along the ammonium event. As seen in Fig. 8, a very similar picture was obtained at DRI using CFA coupled with a TOC analyzer. Although limited, these data highlight three important points. First, the similar OC background levels observed in the dry-drilled Summit-2015-Place ice core and in the wetdrilled North GRIP2 and NEEM cores (Fig. 8), suggest that the use of drill fluid has not significantly contaminated the North GRIP2 and NEEM ice. Second, the carbon input related to biomass burning is more than a factor of 10 higher as OC than as BC. Laboratory experiments by McMeeking et al. (2009) show that, under mixed conditions (flaming and smoldering), at the emission stage, the $\mathrm{OC} / \mathrm{BC}$ ratio would exceed 10. Consistency between these two numbers, however, is likely coincidental since $\mathrm{BC}$ would have a longer atmospheric lifetime than $\mathrm{OC}$ but secondary OC production likely counteracts the larger sink of $\mathrm{OC}$ with respect to $\mathrm{BC}$. Third, given that the ammonium fallout is mainly in the form of ammonium formate (Sect. 3.2.1), a large part of the OC enhancement in ice layers containing biomass-burning material can be attributed to formate. Therefore, the possibility of obtaining high-resolution TOC profiles using CFA offer an excellent complementary tool to ammonium CFA and BC measurements to extract relevant high-resolution biomassburning records from Greenland ice.

\subsubsection{Levoglucosan}

Levoglucosan exclusively is produced by fuel combustion and formed in large quantities by combustion of cellulose (Simoneit et al., 1999) during smoldering. Therefore, levoglucosan has been widely used as tracer of biomass burning. This is even more interesting for boreal fires that are dominated by smoldering. Note, however, that as shown by Kuo et al. (2008), formation of levoglucosan is highly sensitive to the combustion temperature with a yield reaching a maximum around $250^{\circ} \mathrm{C}$. 
Furthermore, several recent laboratory studies have highlighted the existence of various degradation pathways that may be efficient under atmospheric conditions. They involve heterogeneous oxidation by gaseous oxidants (Lai et al., 2014; Henningan et al., 2010, Sang et al., 2016), gas phase oxidation of gaseous levoglucosan (May et al., 2012), and aqueous phase degradation (Holmes et al., 2006; Zhao et al., 2014). These laboratory studies suggest an atmospheric lifetime of levoglucosan against chemical degradation of approximately 2 days (Lai et al., 2014), or from 2 days to 2 weeks (Slade and Knopf, 1013). Given the lower range of estimated levoglucosan lifetime against chemical degradation, we cannot rule out that chemical loss represents a significant loss for levoglucosan additional to the depositional loss that would apply to all biomass-burning aerosol.

\subsubsection{Quality of the different proxies}

The importance of non-biomass-burning sources at a given site with respect to the perturbation associated with arrival of a biomass-burning plume influences the ability of a chemical species to represent a good proxy of fire in ice. The magnitude of the forest-fire perturbation depends on the strength of emission and atmospheric lifetime of the specific chemical species. As discussed for Greenland ice, ammonium, formate, OC (DOC or TOC), BC, as well as vanillic and glycolic acids were enhanced well above their background values during fire events. Levoglucosan would stay in this group of species (denoted as group 1) for which non-biomass-burning sources are relatively weak or do not exist. HCHO also would be in group 1 since biomass burning is expected to represent an important source in the free troposphere of remote regions where its main source is methane oxidation (Lowe and Schmidt, 1983). The use of HCHO as a fire proxy in ice, however, is strongly hampered by large post-depositional effects (see Fig. 4).

In contrast to the preceding species, other significant nonbiogenic sources exist for soluble potassium (sea salt and leachable potassium in dust), nitrate (NO soil emissions and/or lightning), and acetate (vegetation emissions and possibly marine biogenic emissions; Legrand and De Angelis, 1996).

Several other factors should be considered in ranking the different proxies. In group 1, most species can be used regardless of the studied time period, except BC for which, as discussed by McConnell et al. (2007), anthropogenic emissions have grown since 1850 . Since glycolate slowly disappears from ice with time (Sect. 3.2.1), its use as fire proxy is restricted to recent times. Another important consideration when evaluating the ability of different chemical species to trace boreal fire in Greenland ice is the performance of available analytical methods to obtain high-resolution, contamination-free profiles. In group 1, only ammonium, $\mathrm{BC}, \mathrm{OC}$, and vanillic acid can be presently measured with CFA. We emphasize, however, that contamination-free mea- surement of OC in porous firn material (i.e., corresponding to the 2 last centuries in Greenland snow layers) is very difficult (Legrand et al., 2013). Although less significant than for OC, formic acid contamination as a result of firn core storage in sealed plastic bags also is a major concern.

\subsection{Fingerprint of forest fires in mid-latitude, high-elevation glacier ice}

A few attempts previously were made to reconstruct past biomass burning from ice cores extracted at cold glaciers located at mid-northern latitudes. One factor in addressing these mid-latitude records is proximity to the site of permanent large biogenic emissions making use of some proxies that were tested in Greenland difficult (or impossible, in some cases). An exception is Mt. Logan $\left(60^{\circ} 35^{\prime} \mathrm{N}\right.$, $140^{\circ} 35^{\prime} \mathrm{W}$; $5346 \mathrm{~m}$ a.s.1.) located in Yukon (Canada) where ammonium background values are still as low as those observed in Greenland, suggesting a relatively weak contribution of non-biomass-burning sources in this region. On the basis of poor agreement in the occurrence of ammonium events recorded at Summit and at Mt. Logan during the last 250 years, Whitlow et al. (1994) suggested that this site is influenced by the Siberian fires in contrast to Summit which is more influenced by Canadian fires. Note that no analysis of air mass origin has been completed for Mt. Logan.

At lower latitudes, the impact of biogenic sources becomes more important than in Arctic regions. For instance, applying principal component analysis (PCA) to major ions trapped in an ice core extracted from the Belukha glacier in the Siberian Altai Mountains (49 $48^{\prime} \mathrm{N}, 86^{\circ} 34^{\prime} \mathrm{E}$; $4062 \mathrm{~m}$ a.s.1.) covering the last 750 years, Eichler et al. (2011) suggested that ammonium and formate mainly originate from biogenic emissions and that only soluble potassium and nitrate in ice seem to represent good proxies of biomass burning for this region. The importance of biogenic emissions at that site also is evidenced by background values of ammonium and formate being 1 order of magnitude higher than those in Greenland ( $140 \mathrm{ppb}$ of ammonium and $200 \mathrm{ppb}$ of formate; Olivier et al., 2006). It also has to be emphasized that the PCA analysis by Eichler et al. (2011) indicates that, as expected, potassium and nitrate are influenced by large emissions of dust from the central Asia desert.

Another site of interest to trace boreal fires from Siberia is located at Ushkovsky $\left(56^{\circ} 04^{\prime} \mathrm{N}, 160^{\circ} 28^{\prime} \mathrm{E} ; 3903 \mathrm{~m}\right.$ a.s.1.) on the Kamchatka Peninsula, as shown by calculations of air mass back trajectories (Kawamura et al., 2012). At that site, data on major ions (ammonium, formate, and nitrate) are not available but we can suspect that their use as fire proxies is even more complicated than in Altai. The quasi-continuous volcanic emissions that occur in this region may strongly influence deposition of these ions at that site. Instead, more extended use of several organic fire proxies - levoglucosan, vanillic acid, $p$-hydroxybenzoic and dehydroabietic acids was used on this ice core (Kawamura et al., 2012), showing 
some interesting differences both in the occurrence of peaks and the trend in background values. In particular, this work suggests that the levoglucosan signal is from biomass burning over a wider region (Siberia, the Far East, northeast Asia, and southeast Asia) than the one (Siberia) influencing other organics like dehydroabietic acid (a specific tracer of pyrolysis of conifer resin).

\section{Comparison of high-resolution records of biomass-burning proxies in Greenland ice}

In this section, we examine the consistency of different records of boreal fires archived in Greenland ice across different timescales, starting with the most recent times for which more observations are available.

\subsection{Last two centuries}

We compare five ammonium high-resolution records spanning the last two centuries: two from Summit, one from D4, and two from NEEM (Fig. 9). In general, the ammonium peaks tend to be better marked at NEEM than at Summit. The two sites have similar snow accumulation rates, but summer precipitation is more pronounced at NEEM than at Summit (Steen-Larsen et al., 2011). Accordingly, this difference suggests a higher likelihood of a fire imprint in wet deposition at NEEM. Furthermore, as discussed in Sect. 4.1, there is more often direct atmospheric transport from the fire areas to NEEM than to Summit.

Whereas a peak-to-peak comparison is rarely perfect (matches are denoted with a dashed line in Fig. 9), in numerous cases the two sites reveal similar events within a departure of 1 or 2 years (i.e., within the dating errors of individual cores). It seems likely that many of these are actually in the same year and reflect a slight dating error. Note that, even for ice cores drilled in a distance of a few meters at the same site, glaciological noise by wind reworking is high and may lead to a differing imprint of the same event in the snowpack. Accordingly, based on a systematic shallow firn core study on aerosol deposition at the NEEM site, Gfeller et al. (2014) showed that for ammonium a single core archives only 70 to $80 \%$ of the interannual variability in the atmospheric aerosol load, while the rest is obliterated by wind reworking. This finding may explain the differences between the two NEEM records in 1921, 1973, and 1980 (Fig. 9).

During the last two centuries, the consistency is excellent between Summit and D4, whereas some differences appear between Summit and NEEM. The most striking are the absence of record of the 1908 event at NEEM, and the smaller magnitude of the 1863 and 1961 events at NEEM compared to Summit. Conversely, the 1980-1981 events are better detected at NEEM (at least in the 2011 S1 core) than at Summit. The large discrepancy between Summit and NEEM will be discussed in more detail in the following section for the most recent 1961 event. The records for the year 1908 are discussed in Appendix A.

For the most recent years, we examined the extent to which air mass transport influences the record of fire events at a given Greenland site. The main boreal fire sources are Siberia and Alaska/Canada. Data on area burned in Canada are available since 1920 (Van Wagner, 1988) and became more accurate after 1959 with the Canadian National Fire Database (Canadian Forest Service, 2015, National Fire Database Agency Fire Data, Northern Forestry Centre, Edmonton, Alberta; http://cwfis.cfs.nrcan.gc.ca/ha/nfdb) providing precise fire location, start date, and final size (Stocks et al., 2003). Far less precisely known is area burned in Siberia prior to 1997, when satellite data became available. Prior to 1997, only 1915 is known to have been a year of very large fires in Siberia. As discussed below, however, atmospheric transport greatly favors Canada as the main source for Greenland.

Area burned in summer (May to August) in Canada from 1959 to 1992 is reported in Fig. 10, distinguishing between western provinces located west of $96^{\circ} \mathrm{W}$ (British Columbia, Yukon, Alberta, Northwest Territories, Saskatchewan, Manitoba, and Wood Buffalo National Park) and east (Ontario, Quebec, Newfoundland, and Labrador). For these 34 years, maximum area burned occurred in June and July except for 1968, 1977, 1986 (May), and 1981 (August). The increasing burned area during recent years concerned more western than eastern provinces (Stocks et al., 2003). As seen in Fig. 10, total area burned was high in 1961 (3.8 Mha), 1976 (2 Mha), 1980-1981, and 1989 (more than 4 Mha). Prior to 1959, total area burned (not shown) also was high in 1923 and 1929 (3 Mha), 1937 (2 Mha), and 1941 (2 Mha) (Van Wagner, 1998). Considering a possible dating error of 1-2 years, the Greenland ice records consistently indicate ammonium events in 1923, 1929, 1937, 1941, and 1961 (mainly at Summit and D4), and 1980-1981. The relationship between ammonium deposition in Greenland ice and area burned in Canada is poor, however. For instance, an ammonium event was detected at all sites in 1950, a year during which only 1.2 Mha burned in Canada. In contrast, during 1981 in which a maximum of 5.6 Mha burned, only one ice core (NEEM2011-S1; Fig. 9) reveals an outstanding ammonium peak.

Backward trajectories have been computed using the Hybrid Single-Particle Lagrangian Integrated Trajectory model (Stein et al., 2015; available at http://ready.arl. noaa.gov/HYSPLIT.php) with meteorological data from NCEP/NCAR. Reanalysis data are available since 1948 (https://ready.arl.noaa.gov/archives.php). The model was run every $6 \mathrm{~h}$ in backward mode for three different altitudes $(0,250$, and $500 \mathrm{~m}$ above ground level) for May/June/July/August when, as discussed above, the fire activity in Canada (Siberia as well; van der Werf et al., 2006) reached its maximum. Backward air mass trajectory calculations documented the time that air masses reaching Greenland sites were over the forested area of Canada, distinguishing between western and eastern provinces, and north 


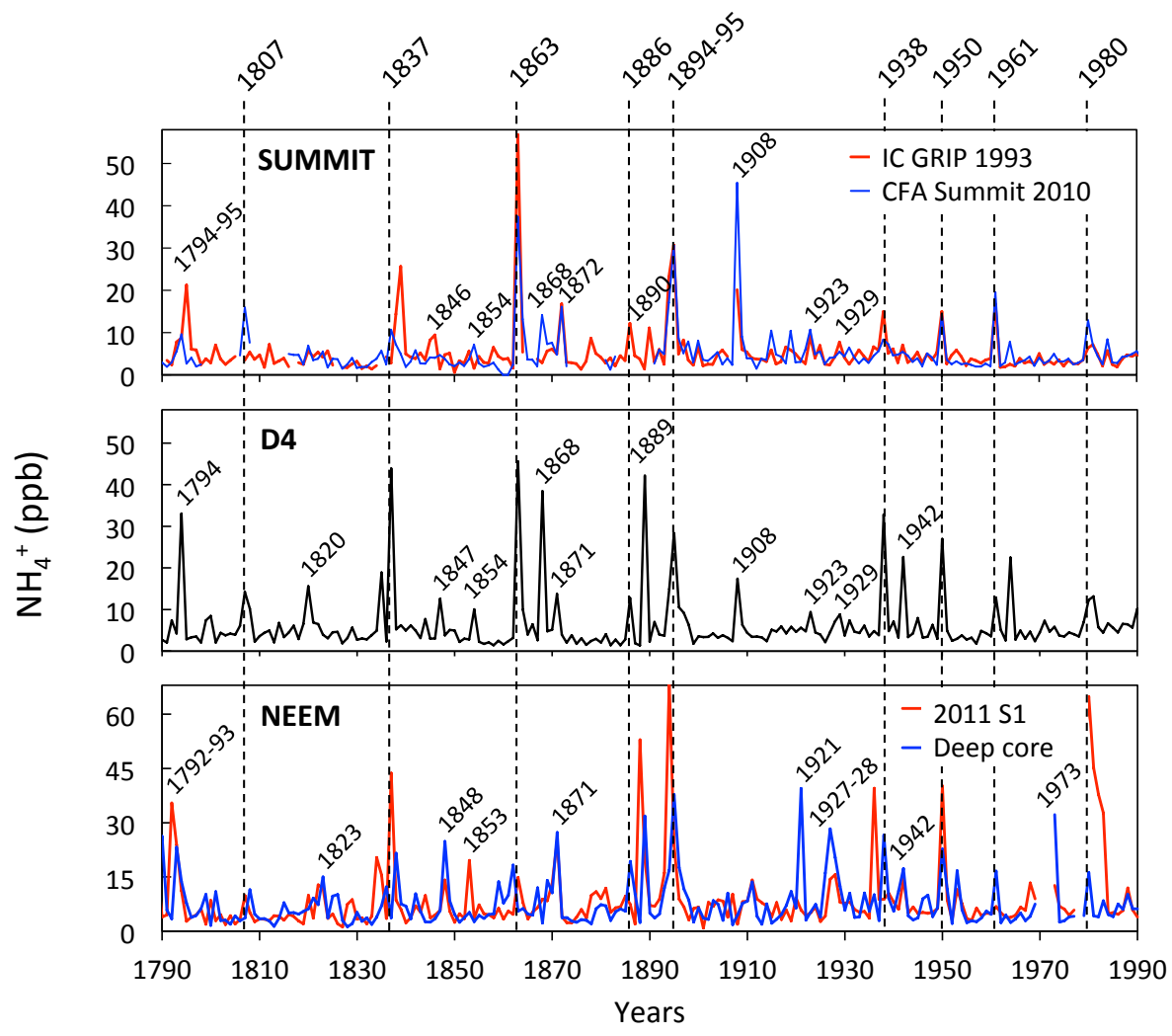

Figure 9. Comparison of several ammonium records obtained at Summit (IC for GRIP 1993, CFA for Summit-2010), D4 (CFA), and NEEM (CFA). All records are seasonally resolved, but data are presented here as annual means. Dashed lines denote the years for which a peak is identified at all sites. The IC GRIP 93 ammonium data are from Legrand and De Angelis (1996).

of $45^{\circ} \mathrm{N}$ in Eurasia, distinguishing between western Europe (from 7 to $45^{\circ} \mathrm{E}$ ) and Siberia (from 45 to $164^{\circ} \mathrm{E}$ ). Comparison of trajectories - arriving at each site at $0,250 \mathrm{~m}$, and $500 \mathrm{~m}$ above ground level - revealed no significant difference. In the following, we report results obtained at $500 \mathrm{~m}$ above ground level. Typical backward trajectories calculated for 5 and 10 days for the Summit and NEEM sites (500 m a.g.l.) are reported for 1978 in Fig. 11, indicating transport that tends to be slower at NEEM than at Summit. As a consequence, considering 10-day backward trajectories, on average in June-July 1978, the time spent over Canada by air masses reaching Greenland was limited to $5.4 \%$ at NEEM compared to $10.8 \%$ at Summit (not shown). This compared to $4.2 \%$ at NEEM and $8.2 \%$ at Summit across 25 years (Table 2). Figure 11 also indicates a larger fraction of time spent over eastern than western Canada at both sites, consistent with the 25 -year averaged values reported in Table 2. For instance, on average the 10-day backward trajectories arriving at NEEM spent $2.6 \%$ of time over eastern Canada against $1.6 \%$ over western Canada $(4.6 \%$ over eastern Canada against $3.0 \%$ over western Canada at Summit). Given the fact that on average in June and July, only in a quarter of cases air mass arriving at Summit (40\% at NEEM) had traveled over North America, over June-July during a total of 4.3 days, the 5-day backward trajectories arriving at Summit had spent at least 1 day over forested areas of Canada (1.4 days at NEEM). For 10-day backward trajectories, the number of days during which the air masses spent more than 1 day reaches 15 days at Summit and 9 days at NEEM. At both sites, when air masses are not coming from North America, they mainly have traveled over the Atlantic Ocean and only rarely (3 to $10 \%$ of cases) had traveled over Eurasia. This summer dominance of air masses coming from North America instead of Eurasia reaching Summit is consistent with other studies (Kahl et al., 1997; Gfeller, 2015). As a result, even for 10-day backward trajectories, the time spent over the fire region of Siberia is $1 \%$ at Summit and $0.4 \%$ at NEEM (Table 2). Interestingly, as shown in Table 2, there is no significant change of air mass origin for summers during which large fires took place in Canada. From this multiple summer analysis of air masses reaching NEEM and Summit sites, we conclude that for species having an atmospheric lifetime of a few days, boreal regions of Canada (in particular eastern provinces) are the main source regions for fire signals archived in Greenland ice.

We now focus on the 1961 event that is well recorded in central Greenland but missed in north Greenland snow layers. With a total area burned of 2.8 Mha (maximum in June 


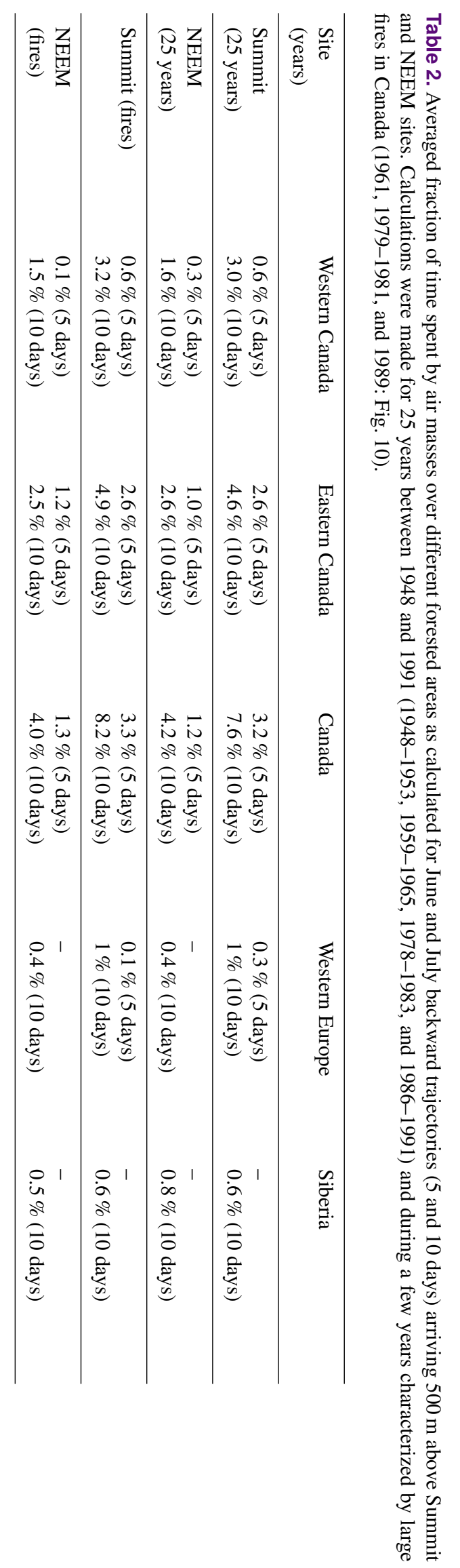



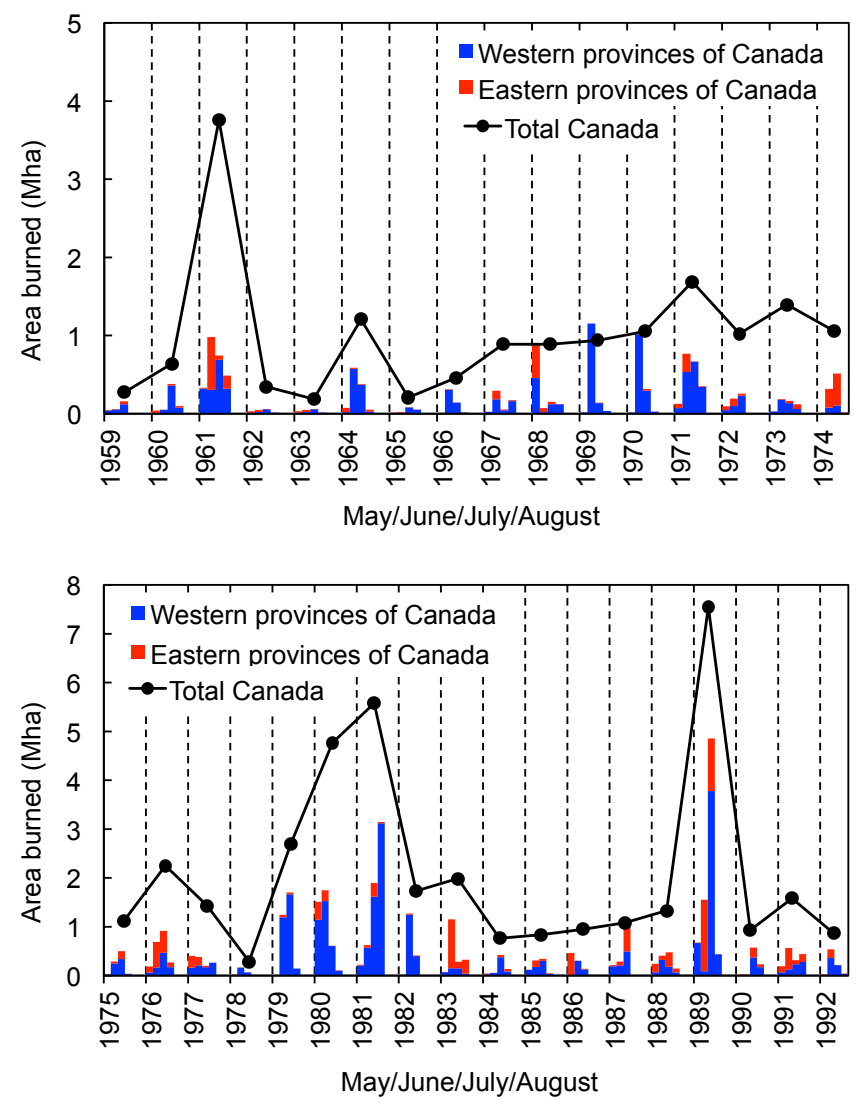

Figure 10. Area burned in Canada from 1959 to 1992 in summer (from May to August), distinguishing western (in red) and eastern (in blue) provinces (data from CNFD: Sect. 4.1). The black curves refer to total area burned in Canada (adapted from Van Wagner, 1988).

with contributions from both western and eastern provinces), 1961 is clearly a particularly high fire activity year of the 1960s and 1970s. In Fig. 12, we reported the starting date of large fires (>200000 ha) having occurred in June and July 1961 together with the fraction of time spent by air masses over western and eastern provinces of Canada reaching the two Greenland sites. Most of the area burned and fire emissions took place during the first 4-8 days after the start of the fire (M. Flannigan, personal communication, 2016), Fig. 12 obviously shows that air masses reaching NEEM had far less sampled 1961 biomass-burning plumes than those arriving at Summit. This example suggests that, in addition to the occurrence of snowfall, atmospheric transport also can modulate the magnitude of deposition of fire debris from site to site in Greenland ice.

\subsection{The last millennium}

The NEEM and Summit ammonium records (annual means) spanning 1190-1990 are compared in Fig. 13. As already seen for the last two centuries, the ammonium peaks tend to be more pronounced at NEEM than at Summit. Again, whereas a peak-to-peak comparison is rarely perfect, the two sites reveal similar events within a departure of 1 or 2 years in numerous cases. Between 1790 and 1490, the agreement generally is good with only a few missed events: 1719 and 1683 events recorded at NEEM but not at Summit (Fig. 13). Between 1490 and $\sim 1300$, agreement is lower and a few peaks are not recorded in one of the two cores (e.g., 1369 and 1465 recorded at NEEM but not at Summit, Fig. 13). Agreement is higher around 1200-1300 perhaps because of the presence of the large sulfate peak attributed to the 1257 Samalas volcanic eruption (Lavigne et al., 2013) which resulted in precise synchronization of the two core records.

To investigate the change in fire frequency during the last 1000 years we deployed a similar peak detection technique as in Fischer et al. (2015) based on a robust outlier detection method (Fischer et al., 1998). The only difference was that, using singular spectrum analysis, we subtracted small background variations (on the order of $2-5 \mathrm{ppb}$ ) from the annual mean $\mathrm{NH}_{4}^{+}$data sets before peak detection (Fischer et al., 1998). For peak detection, all peaks that exceeded the median of a 200-year window by 3.5 times the median of the absolute deviation from the median (MAD) were identified as fire peaks. In a second step, the number of peaks in the 200-year window was counted, where adjacent years identified as peaks were only counted as one. The resulting reduced peak count is shown in Fig. 14 for the three cores.

Despite some decadal variability in each of the three records and some differences between the sites in the overall peak count level, both the two NEEM and Summit ammonium records indicate high fire activity from 1200 to 1500 and after 1850, whereas low fire activity occurred particularly from 1600 to 1800 (Fig. 14). Based on the three records, this finding strengthens the previous conclusion drawn by Savarino and Legrand (1998) on the basis of the 1190-1990 Summit record and suggesting that temporal changes coincide fairly well with the occurrence of the warm and dry climate of the Warm Medieval Period (MWP; 1200-1350) and the cold climate of the Little Ice Age (LIA; 1600 1830). Note that the peak count for each 200 -year window in each core should at first order follow a Poisson distribution. Hence, a peak count of about five peaks per 200 years during the 18th and 17th centuries in the NEEM main core is significantly lower than its counterpart of about 12 peaks 200 years prior to 1400 . Recently, composite series of charcoal records related to northeast boreal fires in North America were obtained (Power et al., 2012), confirming the high fire activity at the transition from the 19th to 20th century and to a lesser extent during MWP, and the very low fire activity at the end of the LIA. 


\section{Summer 1978 backward trajectories}

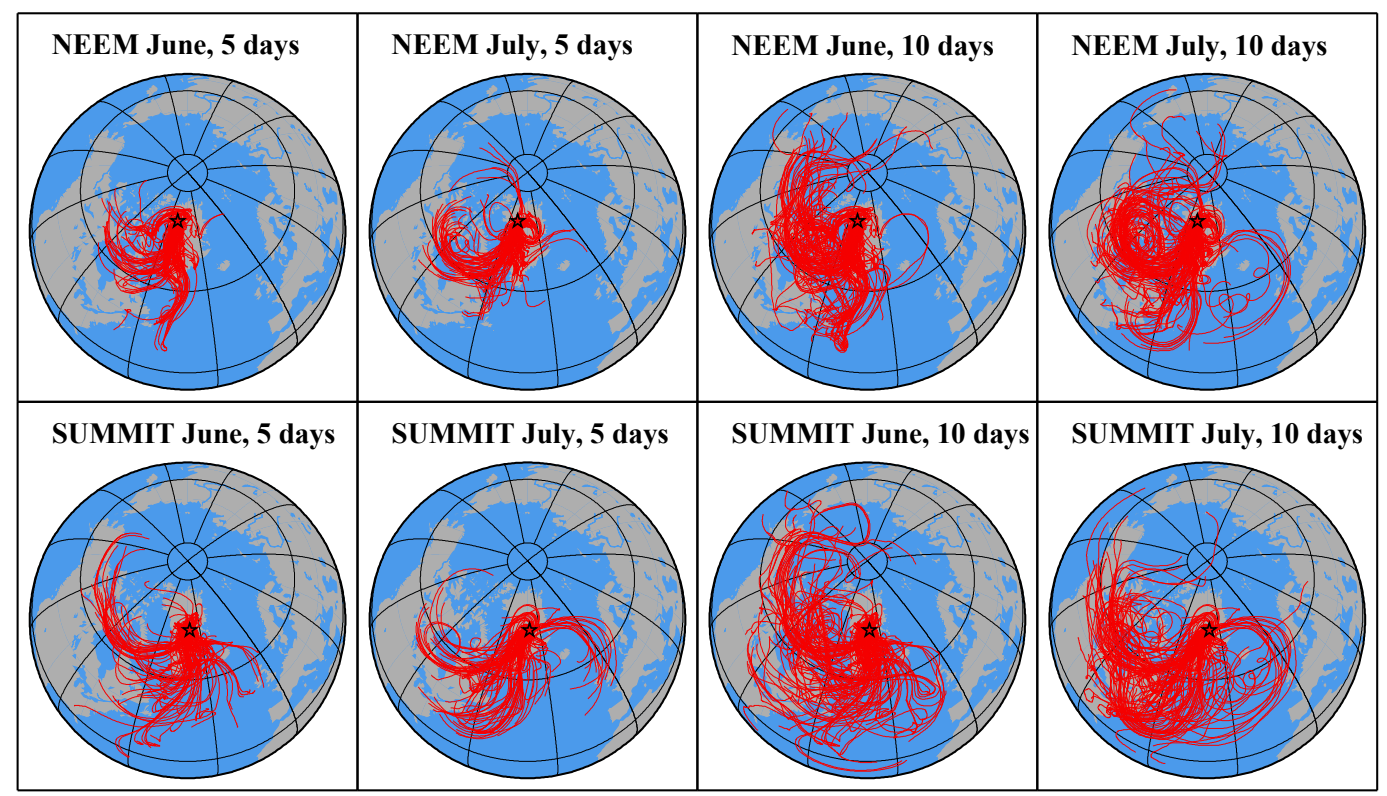

Figure 11. The 5- and 10-day backward air mass trajectories arriving at the NEEM and Summit sites in June and July 1978 (site arrival at $500 \mathrm{~m}$ above ground level).

As discussed previously, comparisons of high-resolution ammonium records with low-resolution levoglucosan records are difficult. To date, the NEEM record (5-year average) of levoglucosan (Zennaro et al., 2014) suggests a different picture for past changes with an outstanding maximum around 1600 (not revealed by the $\mathrm{BC}$ and ammonium profiles). The authors suggested that this high fire activity revealed by the levoglucosan NEEM record was caused by extensively dry conditions in Asia despite the long transport pathway to Greenland. Note that this conclusion conflicts with the hypothesis of a significant chemical degradation of levoglucosan suggested by laboratory studies (Sect. 3.2.5). More work is needed to elucidate why (1) levoglucosan might reflect Siberian fire activity in Greenland ice but not $\mathrm{BC}$ or ammonium, and (2) the finding that the levoglucosan record seems to mirror changes of fire activity at a larger spatial scales (Eurasia plus Canada) than ammonium records.

\subsection{Younger Dryas/Holocene fires}

Several ammonium events were detected during the cold Younger Dryas (YD) climate (11.6-12.8 kyr BP) at Summit (Fuhrer et al., 1996) and NGRIP (Fischer et al., 2015). In their study of the origin of ammonium in Greenland, Melott et al. (2010) suggested that the Haber-like production of ammonium (Appendix A) may have been the cause of the large ammonium peak detected at the onset of the YD in the Summit GISP deep ice core. In their discontinuous study of the deep GRIP Summit ice core, Legrand and De Angelis (1995) measured carboxylates along four events that occurred during the YD period, including the largest one dated at $12610 \mathrm{yr}$ BP and detected by CFA continuous sampling. As seen in Fig. 5, these four ammonium events (open triangles on the formate panel) do not differ from other events with a large increase of formate, the $12610 \mathrm{yr}$ BP event corresponding to the highest ammonium value of $210 \mathrm{ppb}$. Therefore, we rule out the hypothesis of a Haber-like production of ammonium induced by a comet for the ammonium event that occurred at the onset of the YD.

In a recent study, on the basis of a low-resolution levoglucosan record obtained in the deep NEEM ice core (Table 1), Zennaro et al. (2015) reported low fire activity during the YD and the preceding period of Bølling-Allerød (BA; 12.8 $15 \mathrm{kyr} \mathrm{BP}$ ) followed by a steady increase during most of the Holocene (until $2.5 \mathrm{kyr} \mathrm{BP}$ ) that they attributed to changes in fire emissions at the scale of the entire Northern Hemisphere. Although again it is not easy to compare this low-resolution Greenland levoglucosan record with high-resolution ammonium Greenland records, we note that the Greenland ammonium records indicate a different picture. Fischer et al. (2015) on the basis of the high-resolution (10-110 kyr BP) ammonium record obtained from the North GRIP deep ice core indicated an increase of fire activity at the onset of BA, followed by a weak decrease during the $\mathrm{YD}$, and a second increase toward the beginning of the Holocene. For the Holocene, on the basis of the ammonium record at Summit, Fuhrer et al. (1996) reported strong fire activity at $10 \mathrm{kyr}$ BP 

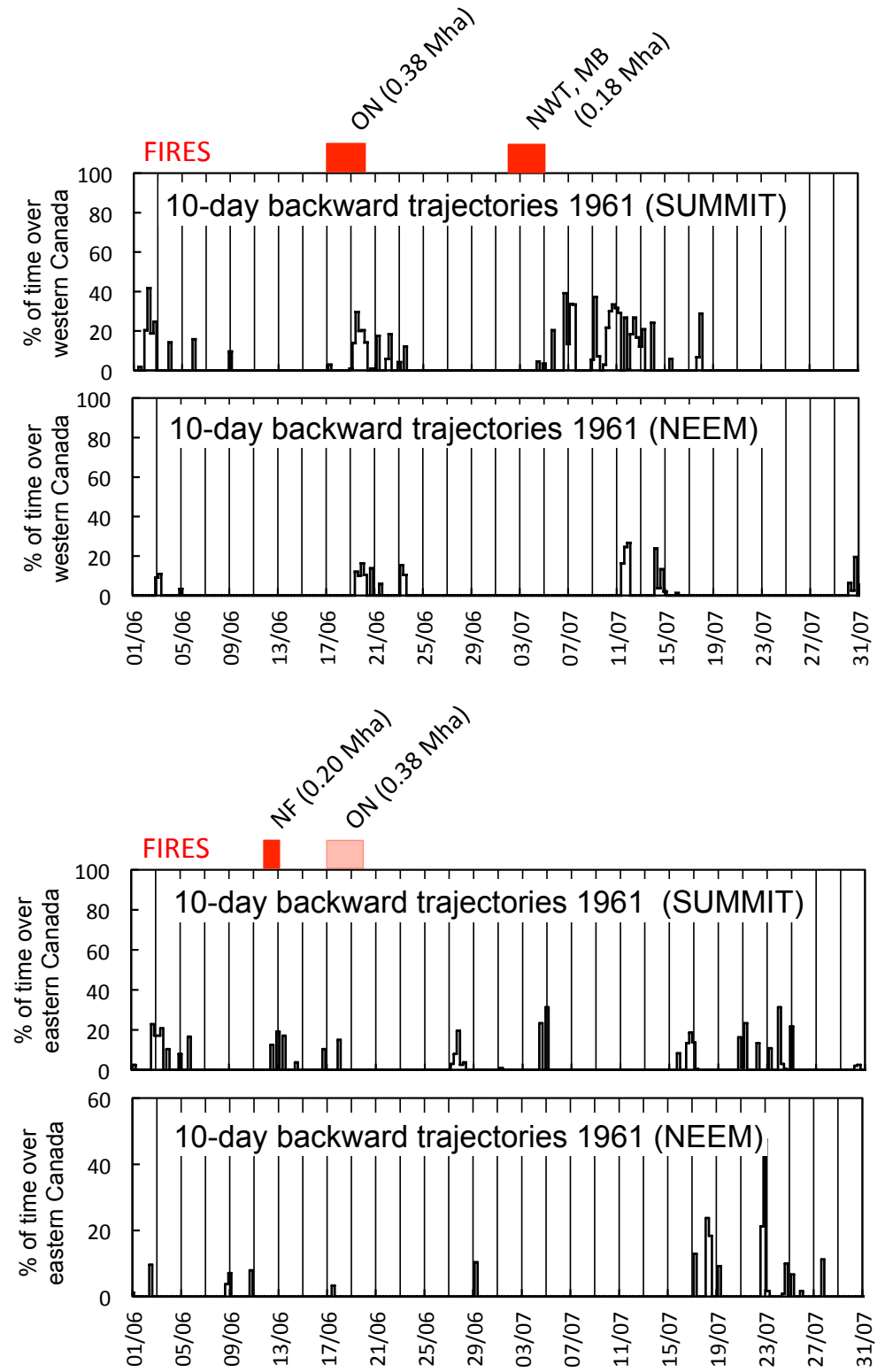

Figure 12. Fraction of time spent by air masses arriving at Summit and NEEM (10-day backward trajectories) at $500 \mathrm{~m}$ a.g.l. and having traveled over a forested area of western (top) and eastern (bottom) provinces of Canada during the severe fire conditions of June/July 1961 (Fig. 10). Some of the largest fires are indicated on top of the panels (red symbols) with corresponding burned area: Ontario and Northwest Territories in the West, Newfoundland and Labrador in the east. The Ontario fire was located in the western portion of the province and we report the red symbol on both panels. Area burned data are from the Canadian National Fire Database (Sect. 4.1).

and an overall decreasing trend throughout the Holocene (Fuhrer et al., 1996). Such a change in trend during the Holocene is consistent with charcoal records from the eastern part of North America (Carcaillet et al., 2002; Marlon et al., 2013). More work is needed to elucidate why levoglucosan and ammonium suggest such different temporal trends. At this stage, we can only emphasize again that the levoglucosan records appear to mirror changes of fire activity at a larger scales (Eurasia plus Canada as discussed in Sect. 4.2 for the last millennium, or even larger as discussed above for the last $15 \mathrm{kyr}$ ) than ammonium and $\mathrm{BC}$ records.

\section{What we have learned: Recommendations for further investigations}

This comparison of various chemical Greenland ice core records permitted evaluation of the quality of different proxies to trace boreal fires. Ammonium, organic fractions (BC 

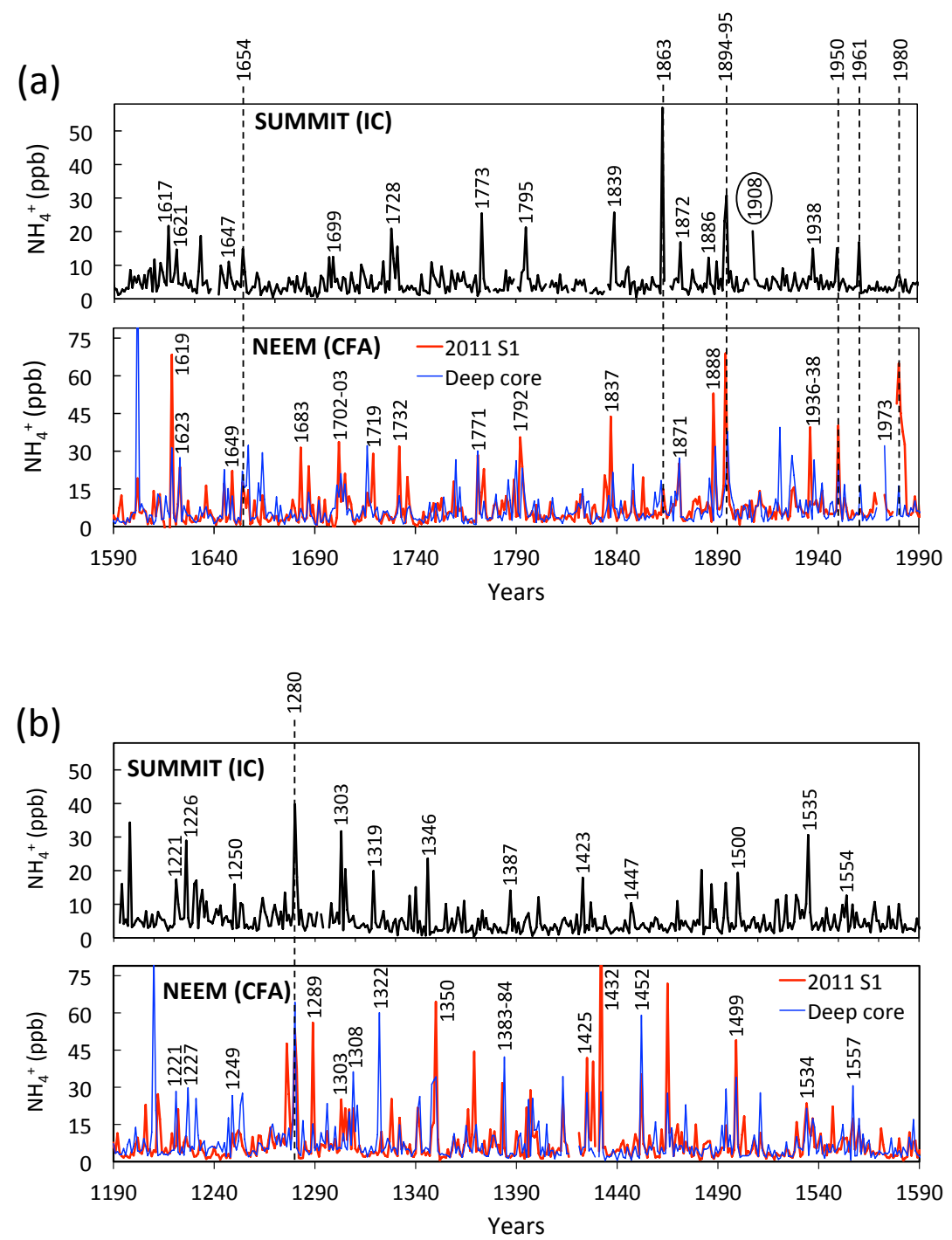

Figure 13. Comparison of ammonium records obtained at Summit and NEEM (NEEM-2011-S1 and the deep core) from 1590 to 1990 (a) and from 1190 to 1590 (b). All records are seasonally resolved, but data are presented here as annual means. Dashed lines denote the years for which a peak is identified in both cores. The Summit data are from Legrand and De Angelis (1996) and Savarino and Legrand (1998).

as well as OC), and organic compounds like formate and vanillic acid are found to be good proxies, whereas the use of potassium, nitrate, and carboxylates (except formate) is complicated by either post-depositional effects or the existence of large non-biomass-burning sources. This comparison also highlighted important factors that may modulate records of such sporadic events including the occurrence of snowfall, wind erosion of snow surface, and atmospheric transport processes and pathways between the source regions of Canada and the different Greenland drill sites. Ammonium ice records consistently indicate Canada as the main source for fire plumes reaching Greenland (in agreement with charcoal records) and suggest past changes in fire activity in response to climatic fluctuations.
From that, we recommend replicate high-resolution CFA measurements - particularly ammonium, TOC, and BC along ice cores extracted from different sites to provide a composite Greenland ice record.

Further work dedicated to high-resolution measurements of levoglucosan also would be welcome. Such measurements would enable improved understanding of the cause of the observed difference in past fire activity changes derived from levoglucosan and ammonium records. A large amount of ice would be needed to achieve high-resolution levoglucosan ice core profiles, but sampling Greenland snow in snow pits would be a useful alternative. For instance, a $5 \mathrm{~m}$ depth pit at Summit would span the last 10 years during which numerous fire events have occurred in North America and Siberia that are well documented by satellite observations. 


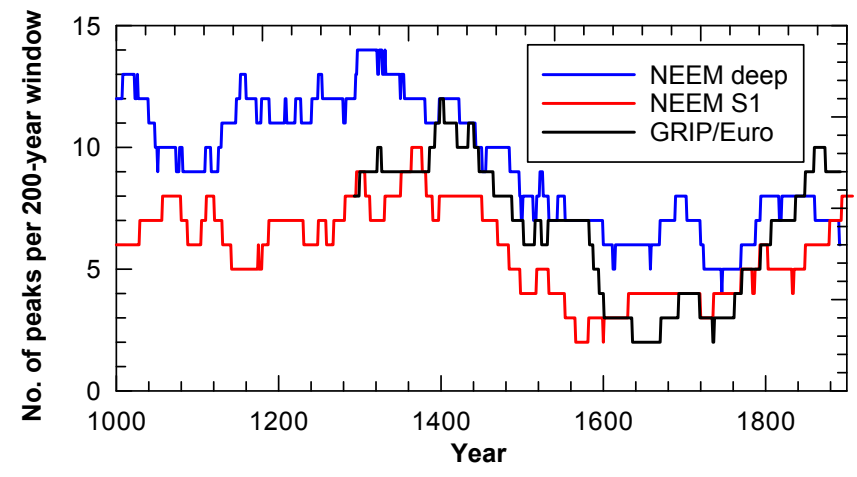

Figure 14. Fire peak frequency in a running 200-year window for the Eurocore at Summit (black), the NEEM deep core (blue), and the NEEM-2011-S1 core (red). Peaks detected in adjacent years were only counted as one.

Finally, field and ice core studies of post-depositional effects for several organic species (or groups of species) are strongly recommended to enable more quantitative interpretation of the ice core archive and implications for past changes in atmospheric chemistry, aerosol and gas phase radiative forcing, and climate.

\section{Data availability}

Data from NEEM-2011-S1, SUMMIT-2010, North GRIP2, D4, and Humboldt can be made available for scientific purposes upon request to J. McConnell at DRI. CFA analyses of ammonium and formaldehyde at GRIP as well as CFA ammonium on the NEEM deep ice core can be made available for scientific purposes upon request to $\mathrm{H}$. Fischer at the Physics Institute and Oeschger Center for Climate Change Research at Bern. IC data from GRIP, GRIP 1993, and Eurocore can be made available upon request to M. Legrand at the Laboratory of Glaciologie et Géophysique de l'Environnement at Grenoble. Canadian fire data are made available by the Canadian Forest Service under http://cwfis.cfs.nrcan.gc.ca/datamart. 


\section{Appendix A: The particular 1908 event}

Whereas the different high-resolution ammonium profiles obtained in various Greenland ice cores covering the last century (Sect. 4.1) are generally in reasonably good agreement, there are some exceptions, including the 1908 summer. This year is unique in that on 30 June 1908, anomalous optical phenomena were observed in the sky over Eurasia. These observations were attributed to the explosion of a cosmic body above the region of the Tunguska River basin in central Siberia $\left(60^{\circ} 55^{\prime} \mathrm{N}, 101^{\circ} 57^{\prime} \mathrm{E}\right)$. A review of this event can be found in Hugues (1976). This event has been the subject of debate regarding several aspects, including the nature of the bolide - a low-density cometary body or stony meteorite. In the first case, accompanying the progressive ablation of the body during its entrance into the atmosphere, thermal decomposition of $\mathrm{N}_{2}$ and $\mathrm{O}_{2}$ would have efficiently produced NO through the mesosphere and stratosphere (Turco et al., 1982). Estimation of the production reached $30 \mathrm{Tg}$ of $\mathrm{NO}$ and would be detected as enhanced nitrate levels in snow deposited in both Greenland and Antarctica during at least one year. Neither from Greenland (Camp Century and Dye 3; Rasmussen et al., 1984) nor from various Antarctic sites (Dome C; Legrand and Delmas, 1986; South Pole; Legrand and Kirchner, 1990) was such a nitrate increase in ice detected. Based on a more accurate aerodynamic model of the bolide, Chyba et al. (1993) suggested that Tunguska was a stony body, which exploded at an altitude of $9 \mathrm{~km}$ with all the energy deposited between 12 and $5 \mathrm{~km}$ altitude. On this basis, Curci et al. (2004) calculated that $0.4 \mathrm{Tg}$ of NO were produced within this elevation range and that nitric acid was mainly deposited downwind within the first month.

Another debate concerned the possibility that a fragment of the Tunguska asteroid survived strong heating within the atmosphere and collided with the ground. For instance, Gasperini et al. (2007) suggested that Lake Cheko, a $300 \mathrm{~m}$ wide lake located a few kilometers from the epicenter of the 1908 Tunguska event, is an impact crater. Based on observational evidence that contradicts this hypothesis (no evidence of an uplifted rim as seen at many fresh impact craters and the presence of unaffected mature trees close to the lake), Collins et al. (2008) concluded that Lake Cheko is highly unlikely to be an impact crater. This debate is of importance with respect to the possibility raised by Melott et al. (2010) that the Tunguska event also may have significantly produced ammonia from nitrogen and hydrogen (the so-called "Haberlike process") under high pressure in the shock front of the bolide. Indeed, such ammonia production needs a sufficient amount of water to proceed and therefore requires the event to have been accompanied by a ground impact. There is a consensus that the shock wave of the Tunguska explosion devastated trees across an area 0.215 Mha (Fast et al., 1967), and the flash-burned vegetation covered an area of about 0.01 Mha. Abramov et al. (2003) estimated that following this event, a total of 0.09 Mha were burned. This burned area remains 1 or 2 orders of magnitude lower than the annual area burned in North America, however (2 Mha on average, up to 7 Mha during some years; Stocks et al., 2003) and in Eurasia (12 Mha on average; Conard et al. 2002).

Figure A1 summarizes sub-annual-resolution $\mathrm{NH}_{4}^{+}$ records from several Greenland ice cores spanning 1905 to 1916. It appears that, for ammonium, 1908 stands out at Summit and D4 but not at NEEM and Humboldt. As discussed in Sect. 3.2.2, an increase of nitrate is sometimes detected along with the ammonium peaks at Summit, but when present, they rarely exceeded a few tens of parts per billion. As seen in Fig. A1, the ammonium event neither at D4 nor at Summit was accompanied by a significant enhancement of nitrate. In contrast to the absence of nitrate peak at Camp Century and Dye 3, two other studies conducted at Summit reported a large nitrate peak in the 1908 layer. McCracken et al. (2001) reported the presence of two narrow sharp spikes (one of them reaching $180 \mathrm{ppb}$ above the usual background in summer) in the nitrate record during 1908, no other relevant species being reported in their study. Melott et al. (2010) reported unpublished data from Summit showing an ammonium peak (200 ppb above the usual background winter level) together with a nitrate peak (around $150 \mathrm{ppb}$ above the usual background winter level) during winter 1908-1909. Both of these studies assigned this ammonium to the Tunguska event. Since the 1908 ammonium event detected in Greenland has a very similar organic signature (an input of ammonium formate at Summit (Fig. 5), and the presence of vanillic acid at D4 (Fig. 6)) compared to other events, we can rule out the hypothesis that an event like Tunguska was able to produce ammonium following the Haber reaction as proposed by Melott et al. (2010). We therefore do not agree with the conclusion from Zennaro et al. (2014), who explained that the absence of levoglucosan and ammonium spikes in the 1908 NEEM ice core suggests that ammonium peaks in other Greenland ice cores may not be caused by forest fires during the 1908 summer but by a Haber-like process as invoked by Melott et al. (2010). Instead, as discussed in Sect. 4.1, the lack of a pronounced 1908 peak at NEEM is likely due to the local character of fire plume transport and/or deposition onto the Greenland ice sheet.

Another point concerning the 1908 event may come from studies conducted in Eurasia. Kawamura et al. (2012) measured biomass-burning organic tracers in an ice core spanning 300 years extracted from the Ushkovsky ice cap. Although discontinuous, the levoglucosan record showed sporadic peaks in $1705,1759,1883,1915,1949$, and 1972 , with the largest peak in 1949. Similarly, vanillic and $p$ hydroxybenzoic acids exhibited peaks in 1705, 1759, and 1949. Although estimates of burned area in Siberia are likely greatly underestimated, the year 1915 was well recognized as a dry year during which a total of $140000 \mathrm{~km}^{2}$ were estimated to have burned in Siberia (Shostakovitch, 1925). Since the high levels of levoglucosan in the 1915 layer of 


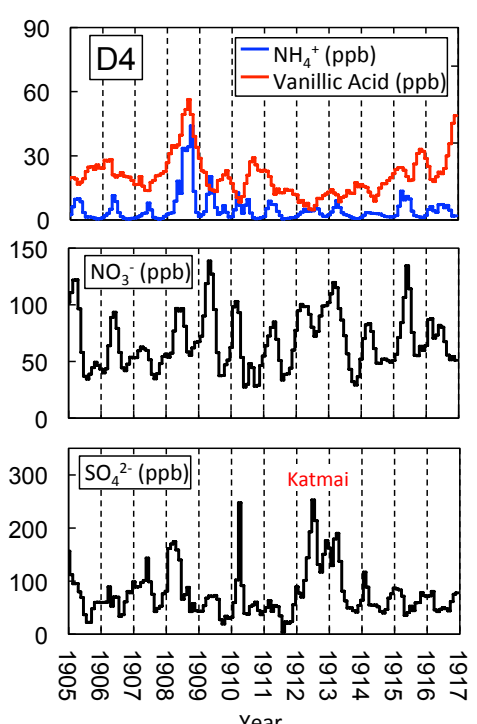

(a)

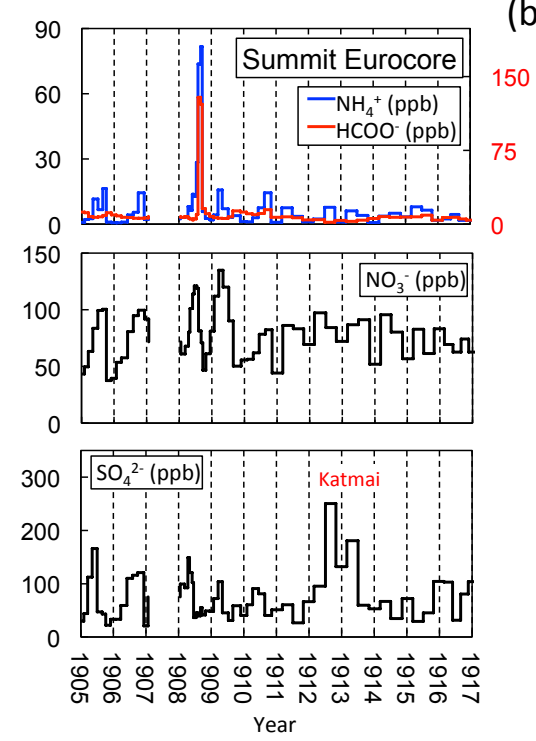

(b)

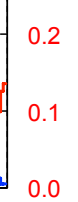

(c)
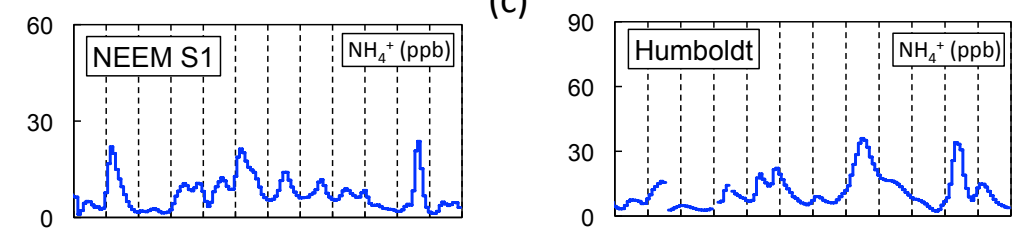

(d)
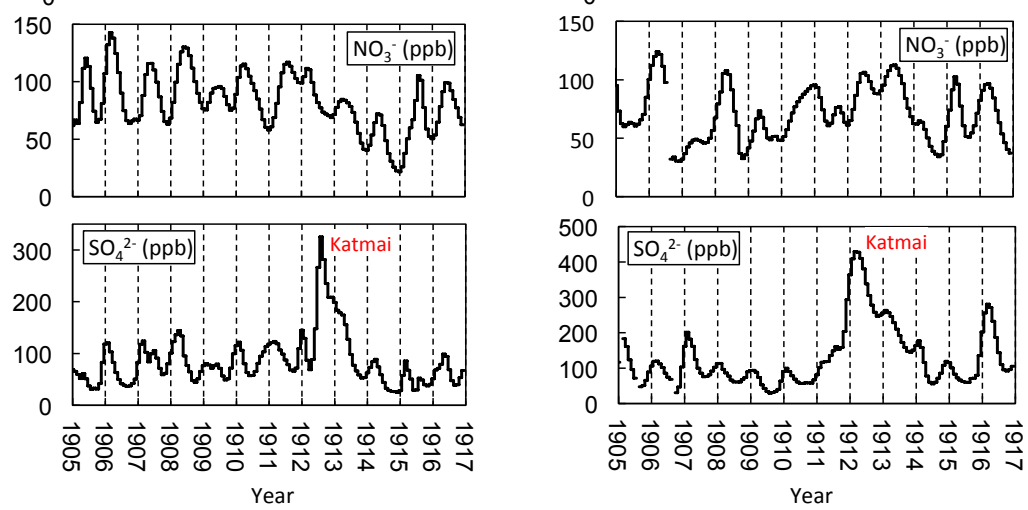

Figure A1. High-resolution 1905-1916 records of ammonium, nitrate, and sulfate at D4 (a), Summit (GRIP 93) (b), NEEM-2011-S1 (c), and Humboldt (d). At Summit and D4, data on carboxylic acids also were available, formate at Summit (Legrand and De Angelis, 1998), and vanillic acid at D4 (McConnell et al., 2007). Note the presence of the Katmai volcanic layer (1912) in the sulfate records, permitting accuracy of the dating to be $<1$ year during this sequence of years.

the Ushkovsky ice core coincides very well with the year of large fires in Siberia and none of the measured biomassburning organic tracers reveal a peak in the 1908 layer of the Ushkovsky ice core, the occurrence of large fires in Siberia in 1908 is unlikely and suggests that the 1908 event seen in some of the Greenland ice record of ammonium originated from North America (as clearly supported by backward trajectory calculations in Sect. 4.1). 
Acknowledgements. We would like to thank Katrin Fuhrer who did CFA chemical measurements at GRIP, Martine De Angelis who helped with IC measurements at GRIP and EUROCORE. Collection, analyses (or reanalysis), and interpretation of the Humboldt, D4, Summit-2010, NEEM-2011-S1, Tunu-2013, and Summit-PLACE ice cores were funded by US NSF grants 0856845, 0909541, 1023672 to DRI, and 1204176 to the University of Rochester. Analyses and interpretation of the North GRIP2 core was support by the University of Oxford's John Fell Fund. We gratefully acknowledge the contributions of the many drilling and logistics personnel involved in the collection and processing of these cores, as well as the students and staff of DRI's Ultra-Trace Chemistry Laboratory. The long-term financial support of ice core research at the University of Bern by the Swiss National Science Foundation (SNF) is gratefully acknowledged. NEEM is directed and organized by the Centre of Ice and Climate at the Niels Bohr Institute and US NSF, Office of Polar Programs. This research also was supported by funding agencies and institutions in Belgium (FNRS-CFB and FWO), Canada (NRCan/GSC), China (CAS), Denmark (FIST), France (IPEV, CNRS/INSU, CEA, and ANR), Germany (AWI), Iceland (RannIs), Japan (NIPR), South Korea (KOPRI), the Netherlands (NWO/ALW), Sweden (VR), Switzerland (SNF), the United Kingdom (NERC), and the United States (US NSF, Office of Polar Programs). We thank Anne-Laure Daniau (EPOC laboratory in Bordeaux, France) for very helpful discussions on charcoal records. She also organized the special session SGF/AFEQ-CNF INQUA on Feux de végétation, poussières minérales et changement climatique: observation et modélisation (2013, Paris, France, coordinated by A.-L. Daniau and Y. Balkanski) during which discussions were launched on fire proxies in ice. We also thank John Little (Natural Resources Canada) for his assistance with the Canadian National Fire Database (CNFD). Lastly, we thank Paul Vallelonga and an anonymous reviewer for helpful comments.

Edited by: T. van Ommen

Reviewed by: P. Vallelonga and one anonymous referee

\section{References}

Abella, L., Nanbu, S., and Fukuda, K.: A theoritical study on levoglucosan pyrolysis reactions yielding aldehydes and a ketone in biomass, Memoirs of the faculty of engineering, Kyushu University, 67, 67-74, 2007.

Abramov, N. G., Arkaev, E. A., and Russkich, F. G.: Fire Research 1908 in the area of the Tunguska meteorite, in: Proceedings of the "Tunguska" State Natural Reserve, Tomsk, Publishing house of Tom, University Press, 1, 275-288, 2003 (in Russian).

Akagi, S. K., Yokelson, R. J., Wiedinmyer, C., Alvarado, M. J., Reid, J. S., Karl, T., Crounse, J. D., and Wennberg, P. O.: Emission factors for open and domestic biomass burning for use in atmospheric models, Atmos. Chem. Phys., 11, 4039-4072, doi:10.5194/acp-11-4039-2011, 2011.

Alvarado, M. J., Logan, J. A., Mao, J., Apel, E., Riemer, D., Blake, D., Cohen, R. C., Min, K.-E., Perring, A. E., Browne, E. C., Wooldridge, P. J., Diskin, G. S., Sachse, G. W., Fuelberg, H., Sessions, W. R., Harrigan, D. L., Huey, G., Liao, J., Case-Hanks, A., Jimenez, J. L., Cubison, M. J., Vay, S. A., Weinheimer, A.
J., Knapp, D. J., Montzka, D. D., Flocke, F. M., Pollack, I. B., Wennberg, P. O., Kurten, A., Crounse, J., St. Clair, J. M., Wisthaler, A., Mikoviny, T., Yantosca, R. M., Carouge, C. C., and Le Sager, P.: Nitrogen oxides and PAN in plumes from boreal fires during ARCTAS-B and their impact on ozone: an integrated analysis of aircraft and satellite observations, Atmos. Chem. Phys., 10, 9739-9760, doi:10.5194/acp-10-9739-2010, 2010.

Alvarado, M. J., Cady-Pereira, K. E., Xiao, Y., Millet, D. B., and Payne, V. H.: Emission Ratios for Ammonia and Formic Acid and Observations of Peroxy Acetyl Nitrate (PAN) and Ethylene in Biomass Burning Smoke as Seen by the Tropospheric Emission Spectrometer (TES), Atmosphere, 2, 633-654, doi:10.3390/atmos2040633, 2011.

Andreae, M. O. and Merlet, P.: Emission of trace gases and aerosols from biomass burning, Global Biogeochem. Cy., 15, 955-966, 2001.

Blarquez, O., Vannière, B., Marlon, J. R., Daniau, A.-L., Power, M. J., Brewer, S., and Bartlein, P. J.: paleofire: An R package to analyse sedimentary charcoal records from the Global Charcoal Database to reconstruct pastbiomass burning, Comput. Geosci., 72, 255-261, 2014.

Cachier, H., Ducret, J., Bremond, M. P., Gaudichet, A., Lacaux, J. P., Yoboue, V., and Baudet, J.: Characterisation of biomass burning aerosols in savanna region of the Ivory Coast, in: Global Biomass Burning, edited by: Levine, J., MIT Press, Cambridge, Mass, 174-180, 1991.

Carcaillet, C., Bouvier, M., Fréchette, B., Larouche, A. C., and Richard, P. J. H.: Comparison of pollen-slide and sieving methods in lacustrine charcoal analyses for local and regional fire history, The Holocene, 11, 467-476, 2001.

Carcaillet, C., Almquist, H., Asnong, H., Bradshaw, R. H. W., Carrión, J. S., Gaillard, M. J., Gajewski, K., Haas, J. N., Haberle, S. G., Hadorn, P., Müller, S. D., Richard, P. J. H., Richoz, I., Rösch, M., Sánchez Goñi, M. F., Von Stedingk, H., Stevenson, A. C., Talon, B., Tardy, C., Tinner, W., Tryterud, E., Wick, L., and Willis, K. J.: Holocene biomass burning and global dynamics of the carbon cycle, Chemosphere, 49, 845-863, 2002.

Chyba, C. F., Thomas, P. J., and Zahnle, K. J.: The 1908 Tunguska explosion: Atmospheric disruption of a stony asteroid, Nature, 361, 40-44, 1993.

Clark, J. S., Stocks, B. J., and Richard, P. J. H.: Climate implications of biomass burning since the 19th century in eastern North America, Glob. Change Biol., 2, 433-442, 1996.

Collins, G. S., Artemieva, N., Wünnemann, K., Bland, P. A., Reimold, W. U., and Koeberl, C.: Evidence that Lake Cheko is not an impact crater, Terra Nova, 20, 165-168, 2008.

Conard, S., Sukhinin, A., Stocks, B., Cahoon, D., Davidenko, E., and Ivanova, G.: Determining effects of area burned and fire severity on carbon cycling and emissions in Siberia, Climatic Change, 55, 197-211, 2002.

Curci, G., Visconti, G., Jacob, D. J., and Evans, M. J.: Tropospheric fate of Tunguska generated nitrogen oxides, Geophys. Res. Lett., 31, L06123, doi:10.1029/2003GL019184, 2004.

de Gouw, J. A., Warneke, C., Stohl, A., Wollny, A. G., Brock, C. A., Cooper, O. R., Holloway, J. S., Trainer, M., Fehsenfeld, F. C., Atlas, E. L., Donnelly, S. G., Stroud, G., and Lueb, A.: Volatile organic compounds composition of merged and aged forest fire plumes from Alaska and western Canada, J. Geophys. Res., 111, D10303, doi:10.1029/2005JD006175, 2006. 
Dhammapala, R., Claiborn, C., Jimenez, J., Corkill, J., Gullett, B., Simpson, C., and Paulsen, M.: Emission factors of PAHs, methoxyphenols, levoglucosan, elemental carbon and organic carbon from simulated wheat and Kentucky bluegrass stubble burns, Atmos. Environ., 41, 2660-2669, 2007.

Dibb, J. E., Talbot, R. W., Whitlow, S. I., Shipham, M. C., Winterle, J., McConnell, J., and Bales, R.: Biomass burning signatures in the atmosphere and snow at Summit, Greenland: An event on 5 August 1994, Atmos. Environ., 30, 553-561, 1996.

Eichler, A., Tinner, W., Brusch, S., Olivier, S., Papina, T., and Schwikowski, M.: An ice-core based history of Siberian forest fires since AD 1250, Quaternary Sci. Rev., 30, 1027-1034, 2011.

Fast, V. G., Boyarkina, A. P., and Bogdanov, M. V.: The destruction caused by the shock wave of the Tunguska meteorite: The problem of the Tunguska meteorite, Tomsk, Publishing house of Tom, University Press, 62-104, 1967 (in Russian).

Fischer, H., Wagenbach, D., and Kipfstuhl, J.: Sulfate and nitrate firn concentrations on the Greenland ice sheet 2, Temporal anthropogenic deposition changes, J. Geophys. Res., 103, 21935 21942, 1998.

Fischer, H., Schüpbach, S., Gfeller, G., Bigler, M., Röthlisberger, R., Erhardt, T., Stocker, T. F., Mulvaney, R., and Wolff, E. W.: Millennial changes in North American wildfire and soil activity over the last glacial cycle, Nat. Geosci., 8, 723-727, doi:10.1038/NGEO2495, 2015.

Flannigan, M., Campbell, I., Wotton, M., Carcaillet, C., Richard, P., and Bergeron, Y.: Future fire in Canada's boreal forest: paleoecology results and general circulation model - regional climate model simulations, Can. J. For. Res., 31, 854-864, 2001.

Flannigan, M. D., Logan, K. A., Amiro, B. D., Skinner, W. R., and Stocks, B. J.: Future area burned in Canada, Climatic Change, 72, 1-16, 2005.

Fuhrer, K., Neftel, A., Anklin, M., and Maggi, V.: Continuous measurements of hydrogen peroxide, formaldehyde, calcium and ammonium concentrations along the new grip ice core from summit, central Greenland, Atmos. Environ., 27, 1873-1880, 1993.

Fuhrer, K., Neftel, A., Anklin, M., Staffelbach, T., and Legrand, M.: High-resolution ammonium ice core record covering a complete glacial-interglacial cycle, J. Geophys. Res.-Atmos., 101, 41474164, 1996.

Gao, S., Hegg, D. A., Hobbs, P. V., Kirchstetter, T. W., Magi, B. I., and Sadilek, M.: Water-soluble organic components in aerosols associated with savanna fires in southern Africa: Identification, evolution, and distribution, J. Geophys. Res.-Atmos., 108, 8491, doi:10.1029/2002jd002324, 2003.

Gasperini, L., Alvisi, F., Biasini, G., Bonatti, E., Longo, G., Pipan, M., Ravaioli, M., and Serra, R.: A possible impact crater for the 1908 Tunguska Event, Terra Nova, 19, 245-251, 2007.

Gfeller, G., Fischer, H., Bigler, M., Schüpbach, S., Leuenberger, D., and Mini, O.: Representativeness of major ions measurements and seasonality derived from NEEM firn cores, The Cryosphere, 8, 1855-1870, doi:10.5194/tc-8-1855-2014, 2014.

Gfeller, G.: What controls chemical aerosol signals in Greenland ice cores, PhD thesis, University of Bern, 2015.

Girardin, M. P., Ali, A. A., Carcaillet, C., Mudelsee, M., Drobyshev, I., Hely, C., and Bergeron, Y.: Heterogeneous response of circumboreal wildfire risk to climate change since the early 1900s, Glob. Change Biol., 15, 2751-2769, 2009.
Hagler, G. S., Bergin, M. H., Smith, E. A., Dibb, J. E., Anderson, C., and Steig, E. J.: Particulate and water-soluble carbon measured in recent snow at Summit, Greenland, Geophys. Res. Lett., 34, L16505, doi:10.1029/2007GL030110, 2007.

Hély, C., Flannigan, M., Bergeron, Y., and McRae, D.: Role of vegetation and weather on fire behavior in the Canadian mixedwood boreal forest using two fire behavior prediction systems, Can. J. Forest Res., 31, 430-441, 2001.

Hennigan, C. J., Sullivan, A. P., Collett, J. L., and Robinson, A. L.: Levoglucosan stability in biomass burning particles exposed to hydroxyl radicals, Geophys. Res. Lett., 37, L09806, doi:10.1029/2010GL043088, 2010.

Holmes, B. J. and Petrucci, G. A.: Soluble Oligomer Formation from Acid-Catalyzed Reactions of Levoglucosan in Proxies of Atmospheric Aqueous Aerosols, Environ. Sci. Technol., 40, 4983-4989, 2006.

Hugues, D.W.: Tunguska revisited, Nature, 259, 626-627, 1976.

Jaffrezo, J.-L., Davidson, C. I., Kuhns, H. D., Bergin, M. H., Hillamo, R., Maenhaut, W., Kahl, J. W., and Harris, J. M.: Biomass burning signatures in the atmosphere of central Greenland, J. Geophys. Res., 103, 31067-31078, 1998.

Kawamoto, H., Murayama, M., and Saka, S., 2003: Pyrolysis behaviour of levoglucosan as an intermediate in cellulose pyrolysis: polymerization into polysaccharide as a key reaction to carbonized product formation, J. Wood Sci., 49, 469-473, 2003.

Kawamura, K., Izawa, Y., Mochida, M., and Shiraiwa, T.: Ice core records of biomass burning tracers (levoglucosan and dehydroabietic, vanillic and $p$-hydroxybenzoic acids) and total organic carbon for past 300 years in the Kamchatka Peninsula, Northeast Asia, Geochim. Cosmochim. Ac., 99, 317-329, doi:10.1016/j.gca.2012.08.006, 2012.

Kahl, J. D. W., Martinez, D. A., Kuhns, H., Davidson, C. I., Jaffrezo, J.-L., and Harris, J. M.: Air mass trajectories to Summit, Greenland: A 44-year climatology and some episodic events, J. Geophys. Res., 102, 26861-26875, 1997.

Kehrwald, N., Zangrando, R., Gabrielli, P., Jaffrezo, J. L., Boutron, C., Barbante, C., and Gambaro, A.: Levoglucosan as a specific marker of fire events in Greenland snow, Tellus B., 64, 18196, doi:10.3402/tellusb.v64i0.18196, 2012.

Kuo, L.-J., Herbert, B. E., and Louchouarn, P.: Can levoglucosan be used to characterize and quantify char/charcoal black carbon in environmental media?, Org. Geochem., 39, 1466-1478, 2008.

Lai, C., Liu, Y., Ma, J., Ma, Q., and He, H.: Degradation kinetics of levoglucosan initiated by hydroxyl radical under different environmental conditions, Atmos. Environ., 91, 32-39, 2014.

Lavigne, F., Degeaib, J.-P., Komorowski, J.-C., Guillet, S., Robert,V., Lahitte, P., Oppenheimer, C., Stoffel, M., Vidal, C. M., Surono, Pratomo, I., Wassmer, P., Hajdas, I., Hadmoko, D. S., and de Belizal, E.: Source of the great A.D. 1257 mystery eruption unveiled, Samalas volcano, Rinjani Volcanic Complex, Indonesia, PNAS, 110, 16742-16747, 2013.

Lefer, B., Talbot, R. W., Harriss, R. H., Bradshaw, J. D., Sandholm, S. T., Olson, J. O., Sachse, G. W., Collins, J., Shipham, M. A., Blake, D. R., Klemm, K. I., Klemm, O., Gorzelska, K., and Barrick, J.: Enhancement of acidic gases in biomass burning impacted air masses over Canada, J. Geophys. Res., 99, 17211737, 1994. 
Legrand M. and De Angelis, M.: Origins and variations of light carboxylic acids in polar precipitation, J. Geophys. Res., 100, 1445-1462, 1995.

Legrand, M. and De Angelis, M.: Light carboxylic acids in Greenland ice: A record of past forest fires and vegetation emissions from the boreal zone, J. Geophys. Res. -Atmos., 101, 4129-4145, 1996.

Legrand, M. and Delmas, R: Relative contributions of tropospheric and stratospheric sources to nitrate in Antarctic snow, Tellus, 38, 236-249, 1986.

Legrand, M. and Kirchner, S: Origins and variations of nitrate in south polar precipitation, J. Geophys. Res., 95, 3493-3507, 1990.

Legrand, M. and Mayewski, P.: Glaciochemistry of polar ice cores: A review, Rev. Geophys., 35, 219-243, 1997.

Legrand, M., De Angelis, M., Staffelbach, T., Neftel, A., and Stauffer, B.: Large perturbation of ammonium and organic-acids content in the Summit-Greenland ice core: Fingerprint from forest fires, Geophys. Res. Lett., 19, 473-475, 1992.

Legrand, M., Angelis, M., Cachier, H., and Gaudichet, A.: Boreal Biomass Burning Over the Last 80 Years Recorded in a SummitGreenland Ice Core, in: Ice Core Studies of Global Biogeochemical Cycles, edited by: Delmas, R., NATO ASI Series, Springer Berlin Heidelberg, 347-360, 1995.

Legrand, M., Preunkert, S., Jourdain, B., Guilhermet, J., Fain, X., Alekhina, I., and Petit, J. R.: Water-soluble organic carbon in snow and ice deposited at Alpine, Greenland, and Antarctic sites: A critical review of available data and their atmospheric relevance, Clim. Past, 9, 2195-2211, doi:10.5194/cp-9-2195-2013, 2013.

Lowe, D. C. and Schmidt, U.: Formaldehyde (HCHO) measurements in the Nonurban Atmosphere, J. Geophys. Res., 88, 10844-10858, 1983.

Marlon, J. R., Bartlein, P. J., Daniau, A. L., Harrison, S. P., Maezumi, S. Y., Power, M. J., Tinner, W., and Vanniere, B.: Global biomass burning: a synthesis and review of Holocene paleofire records and their controls, Quaternary Sci. Rev., 65, 5-25, 2013.

May, A. A., Saleh, R., Hennigan, C. J., Donahue, N. M., and Robinson, A. L.: Volatility of organic molecular markers used for source apportionment analysis: measurements and implications for atmospheric lifetime, Environ. Sci. Technol., 46, 1243512444, 2012.

Mayewski, P, A., Lyons, W.B., Spencer, M. J., Twickler, M. S., Buck, C. F., and Whitlow, S. I.: An ice-core record of atmospheric response to anthropogenic sulfate and nitrate, Nature, 346, 554-556, 1990.

McConnell, J. R., Edwards, R., Kok, G. L., Flanner, M. G., Zender, C. S., Saltzman, E. S., Banta, J. R., Pasteris, D. R., Carter, M. M., and Kahl, J. D. W.: 20th-century industrial black carbon emissions altered arctic climate forcing, Science, 317, 1381-1384, 2007.

McCracken, K. G., Dreschhoff, G. A. M., Zeller, E. J., Smart, D. F., and Shea, M. A.: Solar cosmic ray events for the period 1561994: 1. Identification in polar ice, 1561-1950, J. Geophys. Res., 106, 21585-21598, 2001.

McMeeking, G. R., Kreidenweis, S. M., Baker, S., Carrico, C. M., Chow, J. C., Collett Jr., J. L., Hao, W. M., Holden, A.S., Kirchstetter, T. W., Malm, W. C., Moosmüller, H., Sullivan, A. P., and Wold, C. E.: Emissions of trace gases and aerosols during the open combustion of biomass in the laboratory, J. Geophys. Res., 114, D19210, doi:10.1029/2009JD011836, 2009.

Melott, A. L., Thomas, B. C., Dreschhoff, G., and Johnson, C. K.: Cometary airbursts and atmospheric chemistry: Tunguska and a candidate Younger Dryas event, Geology, 38, 355-358, 2010.

Müller-Tautges, C., Eichler, A., Schwikowski, M., Pezzatti, G. B., Conedera, M., and Hoffmann, T.: Historic records of organic compounds from a high Alpine glacier: influences of biomass burning, anthropogenic emissions, and dust transport, Atmos. Chem. Phys., 16, 1029-1043, doi:10.5194/acp-16-1029-2016, 2016.

Olivier, S., Blaser, C., Brütsch, S., Frolova, N., Gäggeler, H. W., Henderson, K. A., Palmer, A. S., Papina, T., and Schwikowski, M.: Temporal variations of mineral dust, biogenic tracers, and anthropogenic species during the past two centuries from Belukha ice core, Siberian Altai, J. Geophys. Res., 111, D05309, doi:10.1029/2005JD005830, 2006.

Power, M. J., Mayle, F. E., Bartlein, P. J., Marlon, J. R., Anderson, R. S., Behling, H., Brown, K. J., Carcaillet, C., Colombaroli, D., Gavin, D. G., Hallett, D. J., Horn, S.P., Kennedy, L. M., Lane, C.S., Long, C. J., Moreno, P. I., Paitre, C., Robinson, G., Taylor, Z., and Walsh, M. K.: Climatic control of the biomass-burning decline in the Americas after AD 1500, The Holocene, 23, 3-13, doi:10.1177/0959683612450196, 2013.

Preunkert S., Legrand, M., Stricker, P., Bulat, S., Alekhina, I., Petit, J.R., Hoffmann, H., May, B., and Jourdain, B.: Quantification of Dissolved Organic Carbon at very low levels in natural ice samples by a UV induced oxidation method, Environ. Sci. Technol., 45, 673-678, 2011.

Rasmussen, K. L., Clausen, H. B., and Risbo, T.: Nitrate in the Greenland ice sheet in the years following the 1908 Tunguska event, Icarus, 58, 101-108, 1984.

Raven, P. H., Evert, R. F., and Eichorn, S. E.: Biologie végétale, 2nd Edn., De Boeck, (ISBN 978-2-8041-5020-4) and from P. R. Scout, Proceeding of the Ninth Annual California Fertilizer Conference, 2, 15-35, 2007.

Romps, D.M., Seeley, J. T., Vollaro, D., and Molinari, J.: Projected increase in lightning strikes in the United States due to global warming, Science, 346, 851-854, 2014.

Ruellan, S., Cachier, H., Gaudichet, A., Masclet, P., and Lacaux, J. P.: Air-borne aerosols over central Africa during the Experiment for Regional Sources and Sinks of Oxidants (EXPRESSO), J. Geophys. Res., 104, 30673-30690, 1999.

Sang, X. F., Gensch, I., Kammer, B., Khan, A., Kleist, E., Laumer, W., Schlag, P., Schmitt, S. H., Wildt, J., Zhao, R., Mungall, E. L., Abbatt, J. P. D., and Kiendler-Scharr, A.: Chemical stability of levoglucosan: An isotopic perspective, Geophys. Res. Lett., 43, 5419-5424, 2016.

Savarino, J. and Legrand, M.: High northern latitude forest fires and vegetation emissions over the last millennium inferred from the chemistry of a central Greenland ice core, J. Geophys. Res.- Atmos., 103, 8267-8279, 1998.

Shostakovitch, V. B.: Forest conflagrations in Siberia, J. For., 23, 365-371, 1925.

Sigl, M., Winstrup, M., McConnell, J. R., Welten, K. C., Plunkett, G., Ludlow, F., Büntgen, U., Caffee, M., Chellman, N., Dahl-Jensen, D., Fischer, H., Kipfstuhl, S., Kostick, C., Maselli, O. J., Mekhaldi, F., Mulvaney, R., Muscheler, R., Pasteris, D. R., Pilcher, J. R., Salzer, M., Schüpbach, S., Steffensen, J. P., 
Vinther, B. M., and Woodruff, T. E.: Timing and climate forcing of volcanic eruptions for the past 2,500 years, Timing and climate forcing of volcanic eruptions for the past 2,500 years, Nature, 523, 543-549, 2015.

Simoneit, B. R. T.: Biomass burning: a review of organic tracers for smoke from incomplete combustion, Appl. Geochem., 17, 129$162,2002$.

Simoneit, B. R. T., Rogge, W. F., Mazurek, M. A., Standley, L. J., Hildemann, L. M., and Cass G. R.: Lignin pyrolysis products, lignans, and resin acids as specific tracers of plant classes in emissions from biomass combustion, Environ. Sci. Technol., 27, 2533-2541, 1993.

Simoneit, B. R. T., Schauer, J. J., Nolte, C. C., Oros, R. R., Elias, V. O., Fraser, M. P., Rogge, W. F., and Cass, G. R.: Levoglucosan, a tracer for cellulose in biomass burning and atmospheric particles, Atmos. Environ., 33, 17-182, 1999.

Slade, J. H. and Knopf, D. A.: Heterogeneous $\mathrm{OH}$ oxidation of biomass burning organic aerosol surrogate compounds: assessment of volatilisation products and the role of $\mathrm{OH}$ concentration on the reactive uptake kinetics, Phys. Chem. Chem. Phys., 15, 5898-5915, 2013.

Soja, A. J., Tchebakova, N. M., French, N. H. F., Flannigan, M. D., Shugart, H. H., Stocks B. J., Sukhinin, A. I., Parfenova, E. I., Chapin III, F. S., and Stackhouse Jr., P. W.: Climate-induced boreal forest fire change: Predictions versus current observations, Global Planet. Change, 56, 274-296, 2007.

Steen-Larsen, H. C., Masson-Delmotte, V., Sjolte, J., Johnsen, S. J., Vinther, B. M., Bréon, F.-M., Clausen, H. B., Dahl-Jensen, D., Falourd, S., Fettweis, X., Gallée, H., Jouzel, J., Kageyama, M., Lerche, H., Minster, B., Picard, G., Punge, H. J., Risi, C., Salas, D., Schwander, J., Steffen, K., Sveinbjörnsdóttir, A. E., Svensson, A., and White, J.: Understanding the climatic signal in the water stable isotope records from the NEEM shallow firn/ice cores in northwest Greenland, J. Geophys. Res., 116, D06108, doi:10.1029/2010JD014311, 2011.

Stein, A. F., Draxler, R. R, Rolph, G. D., Stunder, B. J. B., Cohen, M. D., and Ngan, F.: NOAA's HYSPLIT atmospheric transport and dispersion modeling system, B. Am. Meteorol. Soc., 96, 2059-2077, 2015.

Stocks, B. J., Mason, J. A., Todd, J. B., Bosch, E. M., Wotton, B. M., Amiro, B. D., Flannigan, M. D., Hirsch, K. G., Logan, K. A., Martell, D. L., and Skinner, W. R.: Large forest fires in Canada, 1959-1997, J. Geophys. Res., 108, D18149, doi:10.1029/2001JD000484, 2003.
Turco, R. P., Toon, O. B., Park, C., Whitten, R. C., Pollack, J. B., and Noerdlinger, P.: An analysis of the physical, chemical, optical, and historical impacts of the 1908 Tunguska meteor fall, Icarus, 50, 1-52, 1982.

Vallelonga, P., Christianson, K., Alley, R. B., Anandakrishnan, S., Christian, J. E. M., Dahl-Jensen, D., Gkinis, V., Holme, C., Jacobel, R. W., Karlsson, N. B., Keisling, B. A., Kipfstuhl, S., Kjær, H. A., Kristensen, M. E. L., Muto, A., Peters, L. E., Popp, T., Riverman, K. L., Svensson, A. M., Tibuleac, C., Vinther, B. M., Weng, Y., and Winstrup, M.: Initial results from geophysical surveys and shallow coring of the Northeast Greenland Ice Stream (NEGIS), The Cryosphere, 8, 1275-1287, doi:10.5194/tc-8-1275-2014, 2014.

Van der Werf, G. R., Randerson, J. T., Giglio, L., Collatz, G. J., Kasibhatla, P. S., and Arellano Jr., A. F.: Interannual variability in global biomass burning emissions from 1997 to 2004, Atmos. Chem. Phys., 6, 3423-3441, doi:10.5194/acp-6-3423-2006, 2006.

Van Wagner, C. E.: The historical pattern of annual area burned in Canada, For. Chron., 64, 182-185, 1988.

Whitlow, S., Mayewski, P., Dibb, J., Holdsworth, G., and Twickler, M.: An ice-core-based record of biomass burning in the arctic and sub-arctic, 1750-1980, Tellus B, 46, 234-242, 1994.

Zennaro, P., Kehrwald, N., McConnell, J. R., Schüpbach, S., Maselli, O. J., Marlon, J., Vallelonga,P., Leuenberger, D., Zangrando, R., Spolaor, A., Borrotti, M., Barbaro, E., Gambaro, A., and Barbante, C.: Fire in ice: two millennia of boreal forest fire history from the Greenland NEEM ice core, Clim. Past, 10, 1905-1924, doi:10.5194/cp-10-1905-2014, 2014.

Zennaro, P., Kehrwald, N., Marlon,J., Ruddiman, W. F., Brücher, T., Agostinelli, C., Dahl-Jensen, D., Zangrando, R., Gambaro, A., and Barbante, C.: Europe on fire three thousand years ago: Arson or climate?, Geophys. Res. Lett., 42, 5023-5033, 2015.

Zhao, R., Mungall, E. L., Lee, A. K. Y., Aljawhary, D., and Abbatt, J. P. D.: Aqueous-phase photooxidation of levoglucosan: a mechanistic study using aerosol time-of-flight chemical ionization mass spectrometry (Aerosol ToF-CIMS), Atmos. Chem. Phys., 14, 9695-9706, doi:10.5194/acp-14-9695-2014, 2014. 